\title{
Attributions in Marriage: Review and Critique
}

\author{
Thomas N. Bradbury and Frank D. Fincham \\ University of Illinois at Urbana-Champaign
}

\begin{abstract}
The prevailing behavioral account of marriage must be expanded to include covert processes. This article therefore examines the attributions or explanations that spouses make for marital events. A review indicates that dissatisfied spouses, compared with satisfied spouses, make attributions for the partner's behavior that cast it in a negative light. Experimental, clinical outcome, and longitudinal data suggest further that attributions may influence marital satisfaction. Rival hypotheses for these findings are examined. Because continued empirical development in this domain depends on conceptual progress, a framework is presented that integrates attributions, behavior, and marital satisfaction. This framework points to several topics that require systematic study, and specific hypotheses are offered for research on these topics. It is concluded that the promising start made toward understanding marital attributions holds considerable potential for enriching behavioral conceptions of marriage.
\end{abstract}

Marital distress has profound and deleterious effects on the physical and emotional well-being of spouses and their children (Bloom, Asher, \& White, 1978) and is the most common reason why people seek psychological help in the United States (Veroff, Kulka, \& Douvan, 1981). As a result, social scientists have shown a longstanding interest in the causes and consequences of marital quality. The focus of research on this topic has shifted over the past several decades, however, and considerable effort is now being expended to understand marital quality in terms of the explanations or attributions that spouses make for events that occur in their marriage. This article offers a review and critical analysis of this growing literature, and a framework is proposed for guiding future studies on attributions in marriage. Before turning to these tasks, we outline briefly the evolution of research on marital quality so that the significance of recent work on marital attributions may be appreciated more fully.

Sociologists conducted the earliest systematic studies on marital quality in the $1920 \mathrm{~s}$, examining in large-sample surveys the association between marital satisfaction and a variety of demographic, personality, and familial variables. Although these pioneering efforts led to numerous contributions on such topics as mate selection, role expectations, and need complementarity (see Burgess, Locke, \& Thomes, 1971; Hicks \& Platt, 1970;

Thomas N. Bradbury was supported in the preparation of this article by a National Research Service Award from the National Institute of Mental Health and by a grant from the National Science Foundation. This article was written while Frank D. Fincham was a Faculty Scholar of the W. T. Grant Foundation and was also supported by National Institute of Mental Health Grant R01 MH44078-0I awarded to Frank D. Fincham.

We thank Greg Miller, John Grych, Chris Scott, and Cindy Yee for their comments on an earlier draft of this article.

Correspondence concerning this article should be addressed to Thomas N. Bradbury, who is now at the Neuropsychiatric Institute, University of California at Los Angeles, Center for Health Sciences, 760 Westwood Plaza, Los Angeles, California 90024-1759, or to Frank D. Fincham, Department of Psychology, University of Illinois, 603 East Daniel Street, Champaign, Illinois 61820.
Tharp, 1963), many of the studies in this research tradition have been characterized as "shotgun in their approach . . . basically atheoretical and aimed at finding out what is there by using all sorts of measuring devices" (Barry, 1970, p. 42).

Recognizing the limits of this body of data, Raush, Barry, Hertel, and Swain (1974) began in 1961 to examine the overt behaviors of couples engaged in improvised marital conflicts in a laboratory setting. This investigation heralded the beginning of a second research tradition, and several studies relating spouse behavior to marital satisfaction soon followed (e.g., Birchler, Weiss, \& Vincent, 1975; Gottman, 1979; Gottman, Markman, \& Notarius, 1977; Vincent, Weiss, \& Birchler, 1975 ). It is known from this research that the problem-solving interactions of distressed spouses, compared with those of nondistressed spouses, are characterized by higher rates of negative behaviors, more reciprocity of negative behaviors, and a greater degree of predictability between spouses' behaviors (for reviews, see Baucom \& Adams, 1987; Schaap, 1984).

Although investigations of marital behavior provide a solid empirical foundation for the study of marriage, there is growing realization that a comprehensive account of marriage must also address the affective and cognitive concomitants of marital interaction (e.g., Bradbury \& Fincham, 1989; Glick \& Gross, 1975; Gottman \& Levenson, 1984; Gurman \& Knudson, 1978; Jacobson \& Moore, 1981; Knudson, Gurman, \& Kniskern, 1980). Indeed, recent years have witnessed a decline in studies of the overt behaviors that differentiate distressed and nondistressed couples, and attention has been devoted instead to investigating a variety of covert variables that might influence marital satisfaction (e.g., dysfunctional beliefs about marriage, Eidelson \& Epstein, 1982; affect and physiological arousal in interaction, Levenson \& Gottman, 1983; perceptual differences between spouses, Arias \& O'Leary, 1985).

The most thoroughly researched topic in this emerging area concerns the attributions that spouses make for events that occur in their marriage. Systematic study of attributions is believed to hold considerable promise for enriching prevailing accounts of marriage because attributions may underlie the patterns of behavior exchange that differentiate distressed and 
nondistressed couples (see Arias \& Beach, 1987; Baucom, 1987; Berley \& Jacobson, 1984; Fincham, 1985b). For example, the common tendency in distressed marriages for a negative behavior of one spouse ("You really should be more pleasant around my parents") to be followed by a negative behavior by the partner ("Don't tell me how to behave!") may be due to the attribution that the partner makes for the spouse's behavior ("He bosses me around because he doesn't care about me or my feelings").

Despite its potential contribution to a broader understanding of marriage, the literature on marital attributions has been criticized recently for having "little coherent direction of movement" and a "lack of focus and direction" (Baucom, Epstein, Sayers, \& Sher, 1989, p. 31). The goals of this article, therefore, are to review and organize the large literature on attributions in marriage, to identify several promising directions for further inquiry, and to offer a framework that might guide such inquiry. To accomplish these goals, our presentation is divided into four principal sections. In the first two sections, we review and evaluate research pertaining to the two questions that have guided nearly all of the research on marital attributions. These questions concern whether there is an association between spouses' attributions for marital events and marital satisfaction and whether this association is causal in form. In the third section, an integrative framework is offered in which the association between attributions and satisfaction is considered in relation to overt behavior in marriage. The utility of the framework is illustrated by applying it to existing research and by using it to identify a number of hypotheses for future study. Finally, the article concludes with a summary of what is known about attributions in marriage and a discussion of the implications of this knowledge for marital research. ${ }^{1}$

\section{Is There an Association Between Attributions and Marital Satisfaction?}

\section{Review}

A first step in determining the relevance of attributions to an understanding of marriage is to examine their association with the degree to which spouses report being satisfied with their relationship. In the absence of a reliable association between attributions and marital satisfaction, the argument for incorporating attributions into a broader theoretical framework of marriage would be difficult to sustain. Although rarely acknowledged, the central idea that guides research on this association derives from observations made by Heider (1958):

If $p$ who dislikes $o$ also benefits $o$, the action will be suspect and ulterior motives will be looked for. The benefit is also less likely to be perceived as a deliberate act than as an accident. However, if $p$ who likes $o$ benefits $o$, there will be less exploration of motives. The benefitting act is more apt to be taken as natural and understandable. (p. 258)

In a similar vein,

Let us suppose $p$ likes $o$, and $p$ perceives or hears that $o$ has done something, which we call $x ; x$ may be something $p$ likes and desires, that is which is positive for $p$, or $x$ may be something which is negative for $p$. If $p$ likes $o$ and $o$ does something positive, this situation is pleasant for $p$; it is fitting and harmonious. . . . However, if the liked $o$ does something that is negative, imbalance results. . . This is an unpleasant situation for $p$. [As one way to redress this imbalance, $] p$ can begin to feel that $o$ is not really responsible for $x$. In this way $x$ cannot be attributed to 0 . . . (p. 207)

Thus it can be hypothesized that, in distressed marriages, attributions for positive events will lessen the impact of those events (e.g., "He only bought me flowers because all his friends were buying gifts for their wives"), and attributions for negative events will accentuate the impact of those events (e.g., "She wouldn't have sex with me because she is trying to get back at me for what I did at the party"). In nondistressed marriages, the opposite pattern of attributions is expected to occur, with the impact of positive events being enhanced (e.g., "He brought me my coffee because he is a considerate person") and the impact of negative events being negated (e.g., "She was angry because she has been working so hard lately").

The 23 studies providing data relevant to these hypotheses are described in Table 1. Common to these investigations is a strategy whereby marital satisfaction is assessed in a sample of spouses and then related to attributions that are made in response to marriagerelevant stimuli. Despite an apparent uniformity of procedure, one can see that there is considerable variety across these studies in the assessment of marital satisfaction, the size and composition of the samples studied, the stimuli used to elicit attributions, and the dependent variables that are investigated.

As might be anticipated on the basis of Heider's (1958) observations, which refer to both the likelihood of an attribution's occurring and the sort of attribution that might occur, a basic distinction exists in Table 1 between those studies that provide information about the occurrence (i.e., rate or number) of attributions and those that provide information about the nature of attributions as rated along a number of dimensions. ${ }^{2}$ Because

\footnotetext{
${ }^{1}$ The focus throughout this article is on attributions made by married people in intact relationships. Hence, little attention is devoted to social psychological research on attributions, in which subjects are typically unacquainted and the relation between attributions and behavior is rarely examined (see Kelley \& Michela, 1980). Coverage of the social psychological literature is limited to those analyses that have implications for conceptualization and measurement of attributions in the marital domain. Research on attributions in special populations, including separated and divorced couples (e.g., Stephen, 1987), dating couples (e.g., J. H. Harvey, Wells, \& Alvarez, 1978; for review, see J. H. Harvey, 1987), abused wives (for review, see Holtzworth-Munroe, 1988), wives of prisoners (Fishman, 1986), and incestuous families (Sagatun, 1982), is also beyond the scope of this review. Finally, we do not discuss the literature on interpersonal perception and phenomenology in marriage. The focus in this literature is considerably more general and varied than our concern with explanations for relationship events, and little attention is given in that area of research to spouses' overt behaviors. In fact, Sillars (1985, p. 278) characterized this domain as lacking "a common research agenda addressing basic issues," thus yielding "relatively little insight" into interpersonal perception in marriage.

${ }^{2} \mathrm{~A}$ further distinction is drawn between the content and the nature of attributions. The content of an attribution refers to the attribution itself (e.g., "We have problems with your parents because you're always afraid to stand up to people and tell them what you really think"), whereas the nature of an attribution is its characterization along a set of dimensions (e.g., the preceding attribution is likely to be seen as internal to the partner, global, and stable). With few exceptions (cf. Epstein, Pretzer, \& Fleming, 1987), the emphasis in the marital literature has been on the nature of attributions.
} 
these two classes of dependent measures may tap different aspects of the attribution process (thus providing different answers to the question of whether attributions and marital satisfaction are associated) and because relatively few studies have examined the rate or number of attributions that occur in response to some event, we direct our attention in this section to research on the nature of attributions. (See Conceptual Integration and Directions for Future Research section for discussion of issues pertaining to the occurrence of attributions.)

\section{The Nature of Attributions and Marital Satisfaction}

The nature of attributions in marriage is typically studied by presenting a spouse with a real or hypothetical marital event and asking the spouse to rate the cause of the event, or the partner's responsibility for the event, along a number of attribution dimensions. The attribution dimensions that have been examined in relation to marital satisfaction are shown in Table 2 , together with the studies in which the dimensions appeared, the operational definitions used to assess them, and the response found to be associated with marital dissatisfaction. This information is provided separately for positive and negative events, and where possible, the results for husbands and wives are also indicated. It can be seen that the nature of attributions has been coded from open-ended questions in some studies, and in some instances analysis of individual dimensions is forgone in favor of examining higher-order constructs representing several dimensions.

The nature of attributions for positive events. Leaving the higher-order attribution constructs aside temporarily, it can be seen that 10 dimensions have been used to investigate the nature of attributions for positive events. As noted earlier, this research was stimulated by the general hypothesis that relationship dissatisfaction will be associated with a tendency to disparage positive partner behavior and to view that behavior in an unfavorable light. However, because considerable progress has been made in delineating the dimensions of attribution since Heider (1958) outlined the relation between liking and attribution, hypotheses of greater specificity can now be offered. In particular, among distressed spouses it is expected that the cause of positive partner behavior will be located outside (or less inside) the partner, will be unstable over time, and will be specific rather than globally influential in marital situations, and that the partner will be seen as having acted unintentionally and with less positive and more negative intent, having little control over the cause of the event, being influenced by a temporary state rather than by a persisting trait, behaving involuntarily, being motivated by selfish concerns, being less deserving of praise, and having a less positive attitude toward the respondent.

In evaluating these hypotheses, the studies reported in Table 2 were designated as offering full support, partial support, or no support for the predicted result on each dimension. Full support and no support were assigned if the reported results were entirely consistent or entirely inconsistent, respectively, with the hypothesis under consideration; partial support was assigned if the reported results varied across spouses (e.g., a significant effect was obtained for husbands but not for wives), across groups (e.g., a significant effect was obtained for clinic spouses but not for distressed community spouses), or across opera- tional definitions of the dimension. The results of this tabulation are shown in Table 3.

Although we recognize the limitations of comparing a large number of studies in a crude fashion (e.g., weighing all studies equally; see Cooper, 1984), the results for individual dimensions can be summarized as follows. First, for those dimensions assessed in at least nine studies, the results are most consistent for the specific versus global dimension. Seven of nine studies support fully the contention that marital dissatisfaction is associated with a tendency to view the causes of positive events as operative in one particular situation rather than in many or all marital situations. In addition, six of nine studies provide at least partial support for the unstable versus stable dimension, with attributions to unstable causes for positive events being indicative of marital dissatisfaction. Less compelling are the results for the locus dimension, where the number of studies providing full support is equal to those providing no support. Failure to find an effect on the locus dimension cannot be ascribed directly to the number of items used in its operational definition as null effects were found using either one or several items.

Turning to the remaining dimensions, each of which has appeared in four or fewer studies, it can be seen that across the intent, selfish versus unselfish motivation, and blameworthy versus praiseworthy dimensions, only one study failed to provide full support for the hypothesis under consideration; this occurred on the intent dimension, where three of four studies were found to offer full support. Although less confidence can be placed in these results because they come from a smaller number of studies, it would appear that an association exists between marital dissatisfaction and the tendency to view positive partner behaviors as less intentional, less positive in intent, motivated by selfish concerns, and less worthy of praise. The single study that examined the attitude dimension found that positive behaviors are less likely to be ascribed to positive attitudes in dissatisfied marriages. Finally, for the uncontrollable versus controllable, trait versus state, and involuntary versus voluntary dimensions, no clear interpretation is possible because in each case one study offered full support and another offered no support for the hypothesis tested.

The nature of attributions for negative events. Investigation of attributions for negative events is particularly germane to the study of marriage because rates and sequences of negative behaviors are known to distinguish the interactions of distressed spouses (e.g., Gottman, 1979) and are also known to be related to spouses' daily ratings of satisfaction (e.g., Jacobson, Waldron, \& Moore, 1980). The nature of attributions for negative relationship events has been examined along 12 dimensions. ${ }^{3}$ Common to the hypotheses offered for these dimensions is the notion that marital dissatisfaction will be associated with a tendency to ascribe a partner's negative behavior to his or her enduring characteristics and to view the partner and the behavior

\footnotetext{
${ }^{3}$ No attempt is made to compare the results for positive and negative partner behavior directly. Such a comparison must be made carefully because results are not necessarily independent (i.e., a single study may include both positive and negative behaviors), and few attempts are made to equate positive and negative behaviors in their degree of affective impact on the respondent (cf. Holtzworth-Munroe \& Jacobson, 1985).
}

(text continues on page 13) 
Table 1

Descriptive Information for Investigations of the Association Between Attributions and Marital Satisfaction

\begin{tabular}{|c|c|c|c|c|}
\hline Study & $\begin{array}{l}\text { Measure of } \\
\text { satisfaction }\end{array}$ & $\begin{array}{l}\text { Sample composition and } \\
\text { mean satisfaction scores }\end{array}$ & Stimuli & Dependent measures \\
\hline \multicolumn{5}{|c|}{ Investigations of negative marital events } \\
\hline $\begin{array}{l}\text { Madden \& Janoff-Bulman, } \\
1981\end{array}$ & $\begin{array}{l}\text { 36-item scale } \\
\text { based on MAT; } \\
\text { possible range, } \\
30-150\end{array}$ & $\begin{array}{l}32 \text { community wives, } 119.62 \\
\text { actual range, } 91-147\end{array}$ & $\begin{array}{l}2 \text { hypothetical conflicts } \\
2 \text { real conflicts }\end{array}$ & $\begin{array}{l}\text { Blame, controllability over } \\
\text { recurrence, stability of } \\
\text { blamed characteristic }\end{array}$ \\
\hline Fincham, 1985a & MAT & $\begin{array}{l}18 \text { clinic couples: husbands, } \\
85.7, \text { wives, } 77.2 \\
19 \text { community couples ( } 13 \\
\text { distressed and } 25 \\
\text { nondistressed spouses): } \\
\text { husbands, } 98.4 \text {; wives, } \\
109.6\end{array}$ & $\begin{array}{l}2 \text { most important } \\
\text { marital difficulties }\end{array}$ & $\begin{array}{l}\text { Locus, globality, stability, } \\
\text { attitude, blame }\end{array}$ \\
\hline Sillars, 1985, Study 1 & $\begin{array}{l}\text { 10-item subscale } \\
\text { from DAS }\end{array}$ & 42 community couples & 10 conflict areas & Blame \\
\hline Sillars, 1985 , Study 2 & $\begin{array}{l}\text { 10-item subscale } \\
\text { from DAS }\end{array}$ & 40 community couples & 10 conflict areas & Blame \\
\hline Sillars, 1985 , Study 3 & $\begin{array}{l}\text { 10-item subscale } \\
\text { from DAS }\end{array}$ & "Approximately 40 couples" & 10 conflict areas & Blame \\
\hline $\begin{array}{l}\text { Epstein, Pretzer, \& } \\
\text { Fleming, } 1987\end{array}$ & DAS & $\begin{array}{l}156 \text { clinic and community } \\
\text { spouses ( } 74 \text { husbands and } \\
82 \text { wives) }\end{array}$ & $\begin{array}{l}23 \text { questions about } \\
\text { causes of marital } \\
\text { problems }\end{array}$ & $\begin{array}{l}\text { Intent, lack of love, } \\
\text { partner's behavior, } \\
\text { partner's personality }\end{array}$ \\
\hline $\begin{array}{l}\text { Fincham \& Bradbury, } \\
1987 \mathrm{c}\end{array}$ & MAT & $\begin{array}{l}34 \text { couples ( } 7 \text { clinic and } 27 \\
\text { community): husbands, } \\
98.4 ; \text { wives, } 103.8\end{array}$ & $\begin{array}{l}2 \text { marital difficulties } \\
3 \text { negative behaviors }\end{array}$ & $\begin{array}{l}\text { Causal attribution } \\
\text { composite: Locus }+ \\
\text { stability + globality } \\
\text { Responsibility attribution } \\
\text { composite: Blame + } \\
\text { intent + motivation }\end{array}$ \\
\hline Fincham \& Beach, 1988 & MAT & $\begin{array}{l}42 \text { clinic wives, } 64.8 \\
42 \text { nondistressed wives, } \\
116.0\end{array}$ & $\begin{array}{l}3 \text { hypothetical } \\
\text { behaviors } \\
\text { Marital problems }\end{array}$ & Blame, intent, motivation \\
\hline
\end{tabular}

Investigations of positive and negative marital events

\begin{tabular}{|c|c|c|c|c|}
\hline $\begin{array}{l}\text { Baucom, Bell, \& Duhe, } \\
\text { 1982, Study } 1\end{array}$ & DAS & $\begin{array}{l}11 \text { clinic couples and } 15 \\
\text { nondistressed couples }\end{array}$ & 24 events from $S O C$ & Locus, stability, globality \\
\hline $\begin{array}{l}\text { Baucom et al., 1982, } \\
\text { Study } 2\end{array}$ & $\begin{array}{l}\text { Daily rating on } 7- \\
\text { point scale for } \\
14 \text { days }\end{array}$ & $\begin{array}{l}13 \text { couples describing } \\
\text { marriage as nondistressed }\end{array}$ & $\begin{array}{l}102 \text { events from } S O C \\
\text { rated for } 14 \text { days }\end{array}$ & $\begin{array}{l}\text { For events that occurred: } \\
\text { Locus, stability, } \\
\text { globality }\end{array}$ \\
\hline Fincham \& O'Leary, 1983 & MAT & $\begin{array}{l}16 \text { clinic couples: husbands, } \\
76.1 \text {; wives, } 65.4 \\
16 \text { nondistressed couples: } \\
\text { husbands, } 124.6 \text {; wives, } \\
127.4\end{array}$ & $\begin{array}{c}12 \text { hypothetical partner } \\
\text { behaviors from SOC }\end{array}$ & $\begin{array}{l}\text { Locus, stability, globality, } \\
\text { controllability }\end{array}$ \\
\hline Fichten, 1984 & MAT & $\begin{array}{l}18 \text { distressed couples, } 63 \\
10 \text { nondistressed couples, } \\
123\end{array}$ & $\begin{array}{l}16 \text { behaviors from } \\
\text { MICS, rated for } \\
\text { typical and actual } \\
\text { disagreements }\end{array}$ & Locus \\
\hline $\begin{array}{l}\text { Holtzworth-Munroe \& } \\
\text { Jacobson, } 1985\end{array}$ & DAS & $\begin{array}{l}22 \text { distressed couples (11 } \\
\text { clinic } 11 \text { community): } \\
\text { husbands, } 86.68 ; \text { wives, } \\
79.05 \\
20 \text { nondistressed couples: } \\
\text { husbands, } 115.85 \text {; wives, } \\
114.50\end{array}$ & $\begin{array}{l}20 \text { partner behaviors } \\
\text { from } S O C \text {, rated for } \\
\text { frequency and } \\
\text { valance }\end{array}$ & $\begin{array}{l}\text { Number and type of } \\
\text { unsolicited and solicited } \\
\text { attributions; for solicited } \\
\text { attributions, locus, } \\
\text { volition, intent, trait/ } \\
\text { state, globality, stability, } \\
\text { attitude }\end{array}$ \\
\hline
\end{tabular}


Table 1 (continued)

\begin{tabular}{|c|c|c|c|c|}
\hline Study & $\begin{array}{l}\text { Measure of } \\
\text { satisfaction }\end{array}$ & $\begin{array}{l}\text { Sample composition and } \\
\text { mean satisfaction scores }\end{array}$ & Stimuli & Dependent measures \\
\hline \multicolumn{5}{|c|}{ Investigations of positive and negative marital events (continued) } \\
\hline $\begin{array}{l}\text { Jacobson, McDonald, } \\
\text { Follette, \& Berley, } 1985\end{array}$ & DAS & $\begin{array}{l}23 \text { distressed couples: } \\
\text { husbands, } 86.70 ; \text { wives, } \\
88.57 \\
49 \text { nondistressed couples: } \\
\text { husbands, } 116.73 \text {; wives, } \\
119.00\end{array}$ & $\begin{array}{l}\text { Positive or negative } \\
\text { behavior of } \\
\text { confederate spouse } \\
\text { in hypothetical } \\
\text { conflict }\end{array}$ & $\begin{array}{l}\text { Subject spouses' locus } \\
\text { rating for confederate's } \\
\text { behavior }\end{array}$ \\
\hline Kyle \& Falbo, 1985 & $\begin{array}{l}\text { 7-item marital } \\
\text { stress index }\end{array}$ & $\begin{array}{l}60 \text { distressed spouses and } 62 \\
\text { nondistressed spouses } \\
\text { (based on median split) }\end{array}$ & $\begin{array}{c}24 \text { hypothetical } \\
\text { behaviors }\end{array}$ & Locus \\
\hline Griffin \& Foster, 1986 & MAT & $\begin{array}{l}15 \text { clinic couples and } 15 \\
\text { nondistressed couples }\end{array}$ & $\begin{array}{l}1 \text { most positive and } 1 \\
\text { most negative feeling } \\
\text { toward partner, daily } \\
\text { for } 7 \text { days }\end{array}$ & $\begin{array}{l}\text { Locus as coded from open- } \\
\text { ended attribution } \\
\text { question }\end{array}$ \\
\hline $\begin{array}{l}\text { Fincham, Beach, \& } \\
\text { Baucom, 1987, } \\
\text { Study I }\end{array}$ & DAS & $\begin{array}{l}22 \text { clinic couples, } 81.5 \\
22 \text { nondistressed couples, } \\
113.7\end{array}$ & $\begin{array}{l}\text { Marital events } \\
\text { occurring in past } 24 \\
\text { hr as indicated on } \\
\text { SOC }\end{array}$ & Locus, stability, globality \\
\hline $\begin{array}{l}\text { Fincham, Beach, \& } \\
\text { Baucom, 1987, } \\
\text { Study } 2\end{array}$ & MAT & $\begin{array}{l}36 \text { clinic spouses, } 73.5 \\
40 \text { nondistressed spouses, } \\
125.8\end{array}$ & $\begin{array}{l}12 \text { hypothetical } \\
\text { behaviors from SOC }\end{array}$ & $\begin{array}{l}\text { Causal attributions: Locus, } \\
\text { stability, globality } \\
\text { Responsibility attributions: } \\
\text { Intent, motivation, } \\
\text { blame }\end{array}$ \\
\hline $\begin{array}{l}\text { Baucom, Sayers, \& Duhe, } \\
\quad 1989\end{array}$ & DAS & $\begin{array}{l}49 \text { clinic couples: husbands, } \\
90.4 \text {; wives, } 84.4 \\
34 \text { community couples: } \\
\text { husbands, } 112.8 \text {; wives, } \\
111.8\end{array}$ & $\begin{array}{l}24 \text { hypothetical partner } \\
\text { behaviors }\end{array}$ & Locus, stability, globality \\
\hline $\begin{array}{l}\text { Holtzworth-Munroe \& } \\
\text { Jacobson, 1988b }\end{array}$ & DAS & $\begin{array}{l}18 \text { successful clinic couples: } \\
\text { Before therapy-husbands, } \\
87.61 \text {; wives, } 87.44 \\
\text { After therapy-husbands, } \\
104.56 \text {; wives, } 108.22 \\
13 \text { nondistressed couples: } \\
\text { husbands, } 116.23 \text {; wives, } \\
113.77\end{array}$ & $\begin{array}{l}\text { No discrete stimuli; } \\
\text { attributions coded } \\
\text { from problem- } \\
\text { solving discussion }\end{array}$ & $\begin{array}{l}\text { Rate of attributions in } \\
\text { relation to aspects of the } \\
\text { event being explained }\end{array}$ \\
\hline
\end{tabular}

Note. Incomplete entries reflect omissions from original sources. MAT = Marital Adjustment Test (Locke \& Wallace, 1959; possible range, 2-158), DAS = Dyadic Adjustment Scale (Spanier, 1976; possible range: 0-151), SOC = Spouse Observation Checklist (Weiss \& Perry, 1979), MICS = Marital Interaction Coding System (Hops, Wills, Patterson, \& Weiss, 1972). 
Table 2

Operational Definitions of Attribution Dimensions and Responses Associated With Marital Dissatisfaction

\begin{tabular}{|c|c|c|}
\hline Study & Operational definition of attribution dimension & Response associated with marital dissatisfaction \\
\hline \multicolumn{3}{|c|}{ Positive events/locus } \\
\hline $\begin{array}{l}\text { Baucom, Bell, \& Duhe, } \\
\text { 1982, Study } 1\end{array}$ & $\begin{array}{l}1 \text { item, } 7 \text {-point scale: Partner or outside circumstances } \\
\text { vs. self }\end{array}$ & $\begin{array}{l}\text { Husbands: Attribution to partner/circumstances } \\
\text { Wives: } n s\end{array}$ \\
\hline Baucom et al., 1982, Study 2 & $\begin{array}{l}3 \text { items, } 7 \text {-point scales (low vs. high): Self, partner, } \\
\text { outside circumstances } \\
\text { Single dimension derived from } 3 \text { items } \\
\text { Partner/circumstances vs. self }\end{array}$ & $\begin{array}{l}\text { Husbands: Less attribution to self and to partner } \\
\text { Wives: Less attribution to self and to partner } \\
\text { Husbands: Attribution to partner/circumstances } \\
\text { Wives: Attribution to partner/circumstances }\end{array}$ \\
\hline Fincham \& O'Leary, 1983 & $\begin{array}{l}1 \text { item, } 7 \text {-point scale: Self/others/outside circumstances } \\
\text { vs. spouse }\end{array}$ & ns \\
\hline Fichten, 1984 & $\begin{array}{l}3 \text { items, 10-point scales (low vs. high): Own personality, } \\
\text { spouse's personality, nature of discussion topic }\end{array}$ & $\begin{array}{l}\text { Attribution to discussion topic (situation) rather } \\
\text { than personalities (dispositions) }\end{array}$ \\
\hline $\begin{array}{l}\text { Holtzworth-Munroe \& } \\
\text { Jacobson, } 1985\end{array}$ & $\begin{array}{l}3 \text { items, 6-point scales (low vs. high): Self, partner, } \\
\text { outside circumstances }\end{array}$ & $\begin{array}{l}\text { Less attribution to partner } \\
\text { Attribution to outside circumstances }\end{array}$ \\
\hline $\begin{array}{l}\text { Jacobson, McDonald, } \\
\text { Follette, \& Berley, } 1985\end{array}$ & $\begin{array}{l}\text { Importance of internal and external explanations for } \\
\text { partner behavior as rated on 5-point scales (low vs. } \\
\text { high) }\end{array}$ & External attributions \\
\hline Kyle \& Falbo, 1985 & 1 item, 6-point scale: Situational vs. dispositional & Attribution to situation \\
\hline Griffin \& Foster, 1986 & $\begin{array}{l}\text { Open-ended responses coded as not partner vs. partner } \\
\text { vs. collaborative }\end{array}$ & $\begin{array}{l}\text { Attribution to not partner } \\
\text { Fewer collaborative attributions }\end{array}$ \\
\hline $\begin{array}{l}\text { Fincham, Beach, \& Nelson, } \\
1987\end{array}$ & $\begin{array}{l}1 \text { item, 7-point scale: Self/others/outside circumstances } \\
\text { vs. spouse }\end{array}$ & $n s$ \\
\hline $\begin{array}{l}\text { Fincham, Beach, \& Baucom, } \\
\text { 1987, Study } 1\end{array}$ & $\begin{array}{l}3 \text { items, 7-point scales (low vs. high): Self, spouse, } \\
\text { outside circumstances }\end{array}$ & ns \\
\hline $\begin{array}{l}\text { Fincham, Beach, \& Baucom, } \\
\quad 1987 \text {, Study } 2\end{array}$ & $\begin{array}{l}1 \text { item, } 7 \text {-point scale: Self/others/outside circumstances } \\
\text { vs. spouse }\end{array}$ & $n s$ \\
\hline $\begin{array}{l}\text { Baucom, Sayers, \& Duhe, } \\
\quad 1989\end{array}$ & $\begin{array}{l}3 \text { items, 7-point scales (low vs. high): Self, partner, } \\
\text { outside circumstances }\end{array}$ & $\begin{array}{l}\text { Husbands: Less attribution to self } \\
\text { Wives: More attribution to outside circumstances }\end{array}$ \\
\hline $\begin{array}{l}\text { Camper, Jacobson, } \\
\text { Holtzworth-Munroe, \& } \\
\text { Schmaling, } 1988\end{array}$ & $\begin{array}{l}4 \text { items, } 6 \text {-point scale (low vs. high): Partner, self, } \\
\text { relationship, outside circumstances }\end{array}$ & $n s$ \\
\hline
\end{tabular}

Positive events/unstable vs. stable

Baucom et al., 1982, Study $1 \quad 1$ item, 7-point scale: Cause will never again be present vs. cause will always be present

Baucom et al., 1982, Study $2 \quad 1$ item, 7-point scale: Cause will never again be present vs. cause will always be present

Fincham \& O'Leary, $1983 \quad 1$ item, 7-point scale: Cause will never again be present vs. cause will always be present

1 item, 6-point scale: Whether behavior would occur frequently in the future

Holtzworth-Munroe \& Jacobson, 1985

Fincham, Beach, \& Nelson, 1987

Fincham, Beach, \& Baucom, 1987, Study 1

Fincham, Beach, \& Baucom, 1987, Study 2

Camper et al., 1988

Baucom, Sayers, \& Duhe, 1989

1 item, 7-point scale: Cause absent vs. present when behavior occurs in the future

1 item, 7-point scale: Cause absent vs. present when behavior occurs in the future

1 item, 7-point scale: Cause absent vs. present when behavior occurs in the future

1 item, 6-point scale: Whether behavior would occur frequently in the future

1 item, 7-point scale: Extent to which cause will be present in the future
Husbands: Attribution to unstable factors

Wives: $n s$

Husbands: $n s$

Wives: Attribution to unstable factors

$n s$

Behavior will occur infrequently in the future

$n s$

ns

Attribution to unstable factors

Behavior will occur infrequently in the future

Husbands: Attribution to unstable factors

Wives: $n s$
Positive events/specific vs. global

Baucom et al., 1982, Study $1 \quad 1$ item, 7-point scale: Cause influences one particular situation vs. all marital situations

Baucom et al., 1982, Study $2 \quad 1$ item, 7-point scale: Cause influences one particular situation vs. all marital situations

Fincham \& O'Leary, $1983 \quad 1$ item, 7-point scale: Cause influences one particular situation vs. all marital situations

1 item, 6-point scale: Cause is specific to one situation vs. present in many areas of marriage

Holtzworth-Munroe \& Jacobson, 1985

Fincham, Beach, \& Nelson, 1987

Fincham, Beach, \& Baucom, 1987, Study 1
1 item, 7-point scale: Cause influences one particular situation vs. all marital situations

1 item, 7-point scale: Cause influences one particular situation vs. all marital situations
Husbands: Attribution to specific factors

Wives: $n s$

Husbands: Attribution to specific factors

Wives: Attribution to specific factors

Attribution to specific factors

Attribution to specific factors

Attribution to specific factors

Attribution to specific factors 
Table 2 (continued)

\begin{tabular}{|c|c|c|}
\hline Study & Operational definition of attribution dimension & Response associated with marital dissatisfaction \\
\hline \multicolumn{3}{|c|}{ Positive events/specific vs. global (continued) } \\
\hline $\begin{array}{l}\text { Fincham, Beach, \& Baucom, } \\
\text { 1987, Study } 2\end{array}$ & $\begin{array}{l}1 \text { item, 7-point scale: Cause influences one particular } \\
\text { situation vs. all marital situations }\end{array}$ & Attribution to specific factors \\
\hline Camper et al., 1988 & $\begin{array}{l}1 \text { item, 6-point scale: Cause affects only one area vs. } \\
\text { virtually all areas of the marriage }\end{array}$ & Attribution to specific factors \\
\hline $\begin{array}{l}\text { Baucom, Sayers, \& Duhe, } \\
\quad 1989\end{array}$ & $\begin{array}{l}1 \text { item, 7-point scale: Extent to which cause will affect } \\
\text { numerous aspects of the relationship }\end{array}$ & $\begin{array}{l}\text { Husbands: Attribution to specific factors } \\
\text { Wives: } n s\end{array}$ \\
\hline \multicolumn{3}{|c|}{ Positive events/intent } \\
\hline $\begin{array}{l}\text { Holtzworth-Munroe \& } \\
\text { Jacobson, } 1985\end{array}$ & $\begin{array}{l}3 \text { items, 6-point scales: Extent to which partner } \\
\text { intended to have an impact on respondent; for } \\
\text { spouses responding affirmatively-degree of } \\
\text { positivity, negativity of impact }\end{array}$ & $\begin{array}{l}\text { Attribution of less intent } \\
\text { Attribution of less positive intent } \\
\text { Attribution of more negative intent }\end{array}$ \\
\hline $\begin{array}{l}\text { Fincham, Beach, \& Nelson, } \\
1987\end{array}$ & $\begin{array}{l}1 \text { item, 7-point scale: Extent to which partner behavior } \\
\text { was intended to be positive vs. negative and } \\
\text { destructive }\end{array}$ & Attribution of less positive intent \\
\hline $\begin{array}{l}\text { Fincham, Beach, \& Baucom, } \\
1987, \text { Study } 2\end{array}$ & $\begin{array}{l}1 \text { item, } 7 \text {-point scale: Extent to which partner behavior } \\
\text { was intended to be positive vs. negative/destructive }\end{array}$ & Attribution of less positive intent \\
\hline Camper et al., 1988 & $\begin{array}{l}3 \text { items, 6-point scales: Whether partner intended to } \\
\text { have an impact on respondent; if so, was intention } \\
\text { positive and/or negative }\end{array}$ & $n s$ \\
\hline
\end{tabular}

Positive events/uncontrollable vs. controllable

Fincham \& O'Leary, 1983

Camper et al., 1988
1 item, 7-point scale: Extent to which cause is controllable by either spouse

1 item, 6-point scale: Whether partner had control over occurrence of the behavior
Attribution to less controllable causes

$n s$

Positive events/trait vs. state
1 item, 6-point scale: Extent to which behavior reflects a personality trait vs. a temporary state

2 items, 6-point scales (low vs. high): Extent to which cause is due to partner's consistent personality traits; extent to which cause is due to partner's temporary state

\section{Attribution to temporary state}

ns

Positive events/involuntary vs. voluntary

\section{Holtzworth-Munroe \& Jacobson, 1985 \\ Camper et al., 1988}

1 item, 6-point scale: Degree to which partner acted voluntarily vs. involuntarily

1 item, 6-point scale: Whether partner acted voluntarily ns

Positive events/selfish vs. unselfish motivation

Fincham, Beach, \& Nelson, 1987

Fincham, Beach, \& Baucom, 1987 , Study 2
1 item, 7-point scale: Extent to which behavior is motivated by selfish vs. unselfish concerns

1 item, 7-point scale: Extent to which behavior is motivated by selfish vs. unselfish concerns
Behavior as involuntary

\section{Positive events/blameworthy vs. praiseworthy}

Fincham, Beach, \& Nelson, 1987

Fincham, Beach, \& Baucom, 1987, Study 2
1 item, 7-point scale: Extent to which behavior is worthy of blame vs. praise

1 item, 7-point scale: Extent to which behavior is worthy of blame vs. praise
Attribution to less unselfish (i.e., more selfish) motivation

Attribution to less unselfish (i.e., more selfish) motivation

\section{Positive events/attitude}

Holtzworth-Munroe \&

Holtzworth-Munroe
Jacobson, 1985

Lavin, 1987
1 item, 6-point scale: Extent to which behavior reflects a positive vs. negative attitude toward respondent
Behavior as less worthy of praise

Behavior as less worthy of praise

Positive events/factorial combination of locus and stability

2 items for each of 4 combinations, 10-point scales (low vs. high):

Internal locus, stable-Extent to which behavior was caused by partner's personality; by attitudes, values, beliefs

Less attribution to internal, stable factors 
Table 2 (continued)

\begin{tabular}{|c|c|c|}
\hline Study & Operational definition of attribution dimension & Response associated with marital dissatisfaction \\
\hline \multicolumn{3}{|c|}{ Positive events/factorial combination of locus and stability (continued) } \\
\hline \multirow[t]{3}{*}{ Lavin, 1987 (continued) } & $\begin{array}{l}\text { Internal locus, variable-Extent to which behavior was } \\
\text { caused by physical or emotional states; by intentions } \\
\text { or efforts }\end{array}$ & More attribution to internal, variable factors \\
\hline & $\begin{array}{l}\text { External locus, stable-Extent to which behavior was } \\
\text { caused by respondent's traits; by topic of discussion }\end{array}$ & $n s$ \\
\hline & $\begin{array}{l}\text { External locus, variable-Extent to which behavior was } \\
\text { caused by factors uncharacteristic of partner; by } \\
\text { experimental circumstances }\end{array}$ & $n s$ \\
\hline \multicolumn{3}{|c|}{ Positive events/distress maintaining vs. relationship enhancing } \\
\hline $\begin{array}{l}\text { Holtzworth-Munroe \& } \\
\text { Jacobson, } 1985\end{array}$ & $\begin{array}{l}\text { Coded responses to indirect and direct requests for } \\
\text { cause of behaviors; scoring categories derived from } \\
\text { combination of attribution dimensions }\end{array}$ & $\begin{array}{l}\text { Indirect requests: Distress maintaining, } n s \text {; lesser } \\
\text { proportion of relationship-enhancing attributions } \\
\text { Direct requests: Greater proportion of distress- } \\
\text { maintaining attributions; relationship enhancing, } \\
n s\end{array}$ \\
\hline Camper et al., 1988 & $\begin{array}{l}\text { Coded responses to indirect and direct requests for } \\
\text { cause of behaviors; scoring categories derived from } \\
\text { combination of attribution dimensions }\end{array}$ & $\begin{array}{l}\text { Indirect requests: Distress maintaining, } n s \text {; } \\
\text { relationship enhancing, } n s \\
\text { Direct requests: Distress maintaining, } n s \text {; } \\
\text { relationship enhancing, } n s\end{array}$ \\
\hline
\end{tabular}

Negative events/locus

Baucom et al., 1982, Study 1

1 item, 7-point scale: Partner or outside circumstances vs. self

Baucom et al., 1982, Study 23 items, 7-point scales (low vs. high): Self, partner, outside circumstances

Single dimension derived from 3 items: Partner/ circumstances vs. self

Fincham \& O'Leary, 1983

Fichten, 1984

Fincham, 1985a

Holtzworth-Munroe \& Jacobson, 1985

Jacobson et al., 1985

Kyle \& Falbo, 1985

Griffin \& Foster, 1986

Fincham, Beach, \& Nelson, 1987

Fincham, Beach, \& Baucom, 1987, Study 1

Fincham, Beach, \& Baucom, 1987, Study 2

Baucom, Sayers, \& Duhe, 1989

Camper et al., 1988
1 item, 7-point scale: Self/others/outside circumstances vs. spouse

3 items, 10-point scales (low vs. high): Own personality, spouse's personality, nature of discussion topic

4 items, 7-point scales (low vs. high): Self, spouse, relationship, outside circumstances

Single dimension derived from [spouse-(self + circumstances)]

Single dimension derived from (spouse-self)

3 items, 6-point scales (low vs. high): Self, partner, outside circumstances

Importance of internal and external explanations for partner behavior as rated on 5-point scales (low vs. high)

1 item, 6-point scale: Situational vs. dispositional

Open-ended responses coded as not partner vs. partner vs. collaborative

1 item, 7-point scale: Self/others/outside circumstances vs. spouse

3 items, 7-point scales (low vs. high): Self, spouse, outside circumstances

1 item, 7-point scale: Self/others/outside circumstances vs. spouse

3 items, 7-point scales (low vs. high): Self, partner, outside circumstances

4 items, 6-point scale (low vs. high): Partner, self, relationship, outside circumstances
Husbands: $n s$

Wives: $n s$

Husbands: More attribution to self, partner, and outside circumstances

Wives: More attribution to self, partner, and outside circumstances

Husbands: $n s$

Wives: $n s$

ns

Attribution to personalities (dispositions) rather than discussion topic (situation)

Comparing nondistressed with clinic spouses: Attribution to partner, relationship

Comparing nondistressed with distressed community spouses: $n s$

$n s$

Attribution to spouse relative to self

Attribution to partner

Less attribution to outside circumstances

Internal attributions

Attribution to disposition

Attribution to partner

Fewer not partner attributions

$n s$

$n s$

Attribution to spouse

Husbands: Attribution to self, partner; less attribution to outside circumstances Wives: Attribution to self, partner ns

\section{Negative events/unstable vs. stable}

Madden \& Janoff-Bulman, 1981

1 item, 5-point scale (low vs. high): Perceived permanence of blamed characteristic

Baucom et al., 1982, Study 1
Greater stability of blamed characteristic

Husbands: $n s$

Wives: Attribution to stable factors
1 item, 7-point scale: Cause will never again be present vs. cause will always be present 
Table 2 (continued)

Study

Operational definition of attribution dimension

Response associated with marital dissatisfaction

Negative events/unstable vs. stable (continued)

Baucom et al., 1982, Study 2

Fincham \& O'Leary, 1983

Fincham, 1985a

\section{Holtzworth-Munroe \&} Jacobson, 1985

Fincham, Beach, \& Nelson, 1987

Fincham, Beach, \& Baucom, 1987, Study 1

Fincham, Beach, \& Baucom, 1987, Study 2

Camper et al., 1988

Baucom, Sayers, \& Duhe, 1989
1 item, 7-point scale: Cause will never again be present vs. cause will always be present

1 item, 7-point scale: Cause will never again be present vs. cause will always be present

1 item, 7-point scale: Cause absent vs. present when difficulty occurs in the future

1 item, 6-point scale: Whether behavior would occur frequently in the future

1 item, 7-point scale: Cause absent vs. present when behavior occurs in the future

1 item, 7-point scale: Cause absent vs. present when behavior occurs in the future

1 item, 7-point scale: Cause absent vs. present when behavior occurs in the future

1 item, 6 -point scale: Whether behavior will occur frequently in the future

1 item, 7-point scale: Extent to which cause will be present in the future
Husbands: Attribution to stable factors Wives: Attribution to stable factors

$n s$

Comparing nondistressed with clinic spouses: $n s$

Comparing nondistressed with distressed community spouses: Attribution to stable factors

Behavior will occur frequently in the future

ns

$n s$

ns

Behavior will occur frequently in the future

Husbands: Attribution to stable factors

Wives: Attribution to stable factors
Negative events/specific vs. global

Baucom et al., 1982, Study 1

1 item, 7-point scale: Cause influences one particular situation vs. all marital situations

Baucom et al., 1982, Study 2

1 item, 7-point scale: Cause influences one particular situation vs. all marital situations

Fincham \& O'Leary, 1983

Fincham, 1985a

1 item, 7-point scale: Cause influences one particular situation vs. all marital situations

1 item, 7-point scale: Cause influences one particular difficulty vs. other areas of marriage

Holtzworth-Munroe \& Jacobson, 1985

Fincham, Beach, \& Nelson, 1987

Fincham, Beach, \& Baucom, 1987 , Study 1

Fincham, Beach, \& Baucom, 1987, Study 2

Camper et al., 1988

Baucom, Sayers, \& Duhe, 1989
$I$ item, 6-point scale: Cause is specific to one situation vs. present in many areas of marriage

1 item, 7-point scale: Cause influences one particular situation vs. all marital situations

1 item, 7-point scale: Cause influences one particular situation vs. all marital situations

1 item, 7-point scale: Cause influences one particular situation vs. all marital situations

1 item, 6-point scale: Cause affects only one area vs. virtually all areas of the marriage

1 item, 7-point scale: Extent to which cause will affect numerous areas of the relationship
Husbands: Attribution to global factors

Wives: Attribution to global factors

Husbands: Attribution of global factors

Wives: Attribution to global factors

Attribution to global factors

Comparing nondistressed with clinic spouses: Attribution to global factors

Comparing nondistressed to distressed community spouses: Attribution to global factors

Attribution to global factors

Attribution to global factors

Attribution to global factors

Attribution to global factors

Attribution to global factors

Husbands: Attribution to global factors

Wives: Attribution to global factors

Negative events/intent

Holtzworth-Munroe \& Jacobson, 1985

Fincham, Beach, \& Nelson, 1987

Fincham, Beach, \& Baucom, 1987, Study 2

Epstein, Pretzer, \& Fleming, 1987

Camper et al., 1988

Fincham \& Beach, 1988
3 items, 6-point scales: Extent to which partner intended to have an impact on respondent; for spouses responding affirmatively-degree of positivity, negativity of impact

1 item, 7-point scale: Extent to which behavior was intended to be positive vs. negative and destructive

1 item, 7-point scale: Extent to which partner behavior was intended to be positive vs. negative/destructive

8 items, 5-point scales (agree vs. disagree): Extent to which respondent attributes problems to malicious intent of partner

3 items, 6-point scales: Whether partner intended to have an impact on respondent; if so, was intention positive and/or negative

1 item, 7-point scale: Extent to which behavior is unintentional vs. intentional
Attribution of more intent

Attribution of less positive intent

Attribution of more negative intent

Attribution of more negative and destructive intent

ns

Attribution of malicious intent

ns

Attribution of more intent 
Table 2 (continued)

\begin{tabular}{|c|c|c|}
\hline Study & Operational definition of attribution dimension & Response associated with marital dissatisfaction \\
\hline \multicolumn{3}{|c|}{ Negative events/uncontrollable vs. controllable } \\
\hline $\begin{array}{l}\text { Madden \& Janoff-Bulman, } \\
1981\end{array}$ & $\begin{array}{l}1 \text { item, } 5 \text {-point scale (low vs. high): How much control } \\
\text { respondent thought she had over recurrence of } \\
\text { problem }\end{array}$ & Less perceived control over recurrence of problem \\
\hline Fincham \& O'Leary, 1983 & $\begin{array}{l}1 \text { item, 7-point scale: Extent to which cause is } \\
\text { controllable by either spouse }\end{array}$ & $n s$ \\
\hline Camper et al., 1988 & $\begin{array}{l}1 \text { item, 6-point scale: Whether partner had control over } \\
\text { behavior }\end{array}$ & $n s$ \\
\hline
\end{tabular}

Negative events/trait vs. state

\section{Holtzworth-Munroe \& Jacobson, 1985}

Epstein et al., 1987

Camper et al., 1988
1 item, 6-point scale: Extent to which behavior reflects a personality trait vs. a temporary state

4 items, 5-point scale (agree vs. disagree): Extent to which respondent attributes problems to partner's personality

2 items, 6-point scales (low vs. high): Extent to which cause is due to partner's consistent personality traits; extent to which cause is due to partner's temporary state

\section{Attribution to personality trait}

Attribution to personality

ns

Negative events/involuntary vs. voluntary

\author{
Holtzworth-Munroe \& \\ Jacobson, 1985 \\ Camper et al., 1988
}

\author{
1 item, 6-point scale: Degree to which partner acted \\ voluntarily vs. involuntarily \\ 1 item, 6-point scale: Whether partner acted voluntarily
}

Behavior as voluntary

$n s$

Negative events/selfish vs. unselfish motivation

Fincham, Beach, \& Nelson, 1987

Fincham, Beach, \& Baucom, 1987, Study 2

Fincham \& Beach, 1988
1 item, 7-point scale: Extent to which behavior is motivated by selfish vs. unselfish concerns

1 item, 7-point scale: Extent to which behavior is motivated by selfish vs. unselfish concerns

1 item, 7-point scale: Extent to which behavior is motivated by selfish vs. unselfish concerns
Attribution to selfish motivation

Attribution to selfish motivation

Attribution to selfish motivation

Negative events/blameworthy vs. praiseworthy

Madden \& Janoff-Bulman,
1981

Fincham, 1985a

Sillars, 1985, Study 1

Sillars, 1985, Study 2

Sillars, 1985, Study 3

Fincham, Beach, \& Nelson, 1987

Fincham, Beach, \& Baucom, 1987, Study 2

Fincham \& Beach, 1988
Respondent asked to divide $100 \%$ of blame for conflict among self, husband, other people, and impersonal world

1 item, 7-point scale (low vs. high): Extent to which spouse is to be blamed for difficulty

1 item, 5-point scale (you vs. your spouse): Extent to which you vs. your spouse is to blame for conflict

1 item, 5-point scale (you vs. your spouse): Extent to which you vs. your spouse is to blame for conflict

1 item, 5-point scale (you vs. your spouse): Extent to which you vs. your spouse is to blame for conflict

1 item, 7-point scale: Extent to which behavior is worthy of blame vs. praise

I item, 7-point scale: Extent to which behavior is worthy of blame vs. praise

1 item, 7-point scale (low vs. high): Extent to which behavior is worthy of blame
Assigning blame to husband

Comparing nondistressed to clinic spouses: $n s$ Comparing nondistressed to distressed community spouses: $n s$

Husbands being blamed by wives

Wives blaming of husbands

Husbands being blamed by wives

Wives blaming of husbands

Husbands: $n s$

Wives: $n s$

Behavior as worthy of blame

Behavior as worthy of blame

ns

\section{Negative events/attitude}

Fincham, 1985a

1 item, 7-point scale (low vs. high): Extent to which cause is due to spouse's negative attitude or feelings toward respondent

Holtzworth-Munroe \& Jacobson, 1985
1 item, 6-point scale: Extent to which behavior reflects a positive vs. negative attitude toward respondent
Comparing nondistressed with clinic spouses: Attribution to negative attitude

Comparing nondistressed with distressed community spouses: Attribution to negative attitude

Attribution to negative attitude 
Table 2 (continued)

\begin{tabular}{ccc}
\hline Study & Operational definition of attribution dimension & Response associated with marital dissatisfaction \\
\hline Epstein et al., 1987 & $\begin{array}{l}\text { Negative events/partner's lack of love } \\
\text { 7 items, 5-point scale (agree vs. disagree): Extent to } \\
\text { which respondent attributes problems to partner's } \\
\text { lack of love }\end{array}$ & Attribution to partner's lack of love \\
\hline
\end{tabular}

Negative events/partner's behavior

Epstein et al., 1987

4 items, 5-point scale (agree vs. disagree): Extent to which respondent attributes problems to partner's behavior

Negative events/factorial combination of locus and stability

Lavin, 1987

2 items for each of 4 combinations, 10-point scales (low vs, high):

Internal locus, stable-Extent to which behavior was caused by partner's personality; by attitudes, values, beliefs

Internal locus, variable-Extent to which behavior was caused by physical or emotional states; by intentions or efforts

External locus, stable-Extent to which behavior was caused by respondent's traits; by topic of discussion

External locus, variable-Extent to which behavior was caused by factors uncharacteristic of partner; by experimental circumstances

Attribution to partner's behavior

\section{Negative events/distress maintaining vs. relationship enhancing}

Holtzworth-Munroe \& Jacobson, 1985

Camper et al., 1988

Coded responses to indirect and direct requests for cause of behaviors; scoring categories derived from combination of attribution dimensions
Indirect requests: Greater proportion of distressmaintaining attributions; lesser proportion of relationship-enhancing attributions

Direct requests: Greater proportion of distressmaintaining attributions

Relationship enhancing: $n s$

Indirect requests: Distress maintaining, $n s$, relationship enhancing, $n s$

Direct requests: Distress maintaining, $n s$, relationship enhancing, $n s$

Negative events/causal attribution composite

Fincham \& Bradbury, 1987c 3 items, 7-point scales: Summary index based on extent

Attribution to spouse and to global and stable factors to which cause lies in spouse (low vs. high);

influences one vs. other areas of marriage; is likely to

be absent vs. present when event occurs in the future

\section{Negative events/ responsibility attribution composite}

Fincham \& Bradbury, 1987c

3 items, 7-point scales: Summary index based on extent to which event is worthy of blame (low vs. high); unintentional vs. intentional; reflective of unselfish vs. selfish motivation

Behavior as blameworthy, intentional, and selfishly motivated

Note. $n s=$ Not significant. The data reported by Baucom et al. (1982, Study 2$)$ were analyzed with $t$ tests and correlations. Because the latter analysis is inappropriate for their extreme-group design (i.e., comparing couples either high or low in satisfaction), the results obtained using $t$ tests are shown. In their longitudinal study, Fincham and Bradbury (1987b) reported significant correlations between satisfaction and attribution composites at two points in time. Because the results were the same at both points, they are not distinguished here.

in a critical light. Thus, it is expected that the cause of negative events will be seen as internal (or less external) to the partner and the relationship and will be stable over time, globally influential across marital situations rather than specific to one or a few situations, and related to the partner's behavior. In addition, the partner will be seen as having acted intentionally and with less positive and more negative intent, having control over the cause of the event (with the respondent having little control over the cause), being influenced by a persisting trait rather than by a temporary state, behaving voluntarily, being motivated by selfish concerns, deserving of blame, and as having a less positive attitude toward, and a lack of love for, the respondent.

As with positive events, investigations of attributions for negative events were designated as offering full support, partial support, or no support for the hypothesis on each dimension. For those dimensions examined in at least 6 studies, effects were again most consistent on the specific versus global dimension. In fact, in all 10 studies an association is evident between mari- 
Table 3

Degree of Support for Attribution Dimensions Measured for Positive and for Negative Marital Events

\begin{tabular}{lllll}
\hline & \multicolumn{2}{c}{ Degree of support } \\
\cline { 3 - 4 } Attribution dimension & $\begin{array}{c}\text { Number of } \\
\text { studies }\end{array}$ & $\frac{\text { Full }}{n} \%$ & $\frac{\text { Partial }}{n} \%$ & $\frac{n}{n} \%$ \\
\hline
\end{tabular}

Positive events

\begin{tabular}{lcrrrrrr} 
Locus & $13^{\text {a }}$ & 5 & 42 & 2 & 17 & 5 & 42 \\
Unstable vs. stable & 9 & 3 & 33 & 3 & 33 & 3 & 33 \\
Specific vs. global & 9 & 7 & 78 & 2 & 22 & 0 & 0 \\
Intent & 4 & 3 & 75 & 0 & 0 & 1 & 25 \\
Uncontrollable vs. controllable & 2 & 1 & 50 & 0 & 0 & 1 & 50 \\
Trait vs. state & 2 & 1 & 50 & 0 & 0 & 1 & 50 \\
Involuntary vs. voluntary & 2 & 1 & 50 & 0 & 0 & 1 & 50 \\
Selfish vs. unselfish motivation & 2 & 2 & 100 & 0 & 0 & 0 & 0 \\
Blameworthy vs. praiseworthy & 2 & 2 & 100 & 0 & 0 & 0 & 0 \\
Attitude & 1 & 1 & 100 & 0 & 0 & 0 & 0 \\
\hline
\end{tabular}

Negative events

\begin{tabular}{lrrrrrrr} 
Locus & $14^{\mathrm{a}}$ & 5 & 38 & 4 & 31 & 4 & 31 \\
Unstable vs. stable & 11 & 5 & 45 & 2 & 18 & 4 & 36 \\
Specific vs. global & 10 & 10 & 100 & 0 & 0 & 0 & 0 \\
Blameworthy vs. praiseworthy & 8 & 3 & 38 & 2 & 25 & 3 & 38 \\
Intent & 6 & 4 & 67 & 0 & 0 & 2 & 33 \\
Uncontrollable vs. controllable & 3 & 1 & 33 & 0 & 0 & 2 & 67 \\
Trait vs. state & 3 & 2 & 67 & 0 & 0 & 1 & 33 \\
Selfish vs. unselfish motivation & 3 & 3 & 100 & 0 & 0 & 0 & 0 \\
Involuntary vs. voluntary & 2 & 1 & 50 & 0 & 0 & 1 & 50 \\
Attitude & 2 & 2 & 100 & 0 & 0 & 0 & 0 \\
Partner's lack of love & 1 & 1 & 100 & 0 & 0 & 0 & 0 \\
Partner's behavior & 1 & 1 & 100 & 0 & 0 & 0 & 0 \\
\hline
\end{tabular}

Note. Full support and no support were assigned to a study if the reported results were entirely consistent or inconsistent, respectively, with the hypothesis under consideration. Partial support was assigned if the reported results varied across spouses, groups, or operational definitions of the dimension. Where possible, the endpoint of the attribution dimension that is hypothesized to be associated with marital dissatisfaction is shown in italics. Because of rounding errors, percentage values for a given dimension may not sum to $100 \%$.

${ }^{a}$ As Baucom, Bell, and Duhe (1982, Study 1) noted, because of item wording their study provides inconclusive evidence for the locus dimension.

tal dissatisfaction and the tendency to view the causes of negative relationship events as globally influential in the marriage rather than limited to specific situations. Evidence also emerges for an association between marital dissatisfaction and ascribing negative events to the partner, as 9 of 13 studies provided either full or partial support for the locus dimension. In 4 of 6 studies marital dissatisfaction was related to a tendency to infer more intent or more negative intent for negative relationship events. Finally, on the unstable versus stable and blameworthy versus praiseworthy dimensions, full or partial support was found in 7 of 11 and 5 of 8 studies, respectively. ${ }^{4}$

Of the dimensions that have appeared in three or fewer studies, results suggest that marital dissatisfaction is associated with viewing negative relationship events as being motivated by selfish concerns (full support in three of three studies) and reflective of a negative attitude toward the respondent (full support in two of two studies). Some support has also been obtained for the trait versus state dimension, suggesting a relation between marital dissatisfaction and the attribution of negative events to personality traits (full support in two of three studies). In addition, attributing negative events to the partner's lack of love and to the partner's behavior may also relate to marital dissatisfaction (full support for both dimensions in one of one studies). Effects on the remaining dimensions are either equivocal (involuntary vs. voluntary) or less likely than obtaining no effect (uncontrollable vs. controllable).

Higher-order attribution constructs. Before considering in greater detail the degree of confidence that can be placed in the preceding results, we first discuss the rationale for summarizing data across several attribution dimensions to produce higherorder constructs and the results of studies in which this has been done.

One reason for studying higher-order attribution constructs is a conceptual one and follows from the observation that interpretations of research findings and theoretical writings on attributions in marriage (e.g., Baucom, 1987; Berley \& Jacobson, 1984) typically highlight the importance of response patterns across attribution dimensions and offer few specific implications for individual dimensions. Because of this, Fincham and Bradbury (1987c), in a study of attributions for negative marital events, computed two composite indices per spouse. This was accomplished by adding responses to the locus (attribution to spouse), specific versus global, and unstable versus stable dimensions to form a causal attribution index and by adding responses to the blameworthiness, unintentional versus intentional, and unselfish versus selfish motivation dimensions to form a responsibility attribution index. Higher scores on the composite indices reflect a less benign pattern of attributions. Coefficient alpha values for these indices ranged from .73 to .83 . As anticipated, both indices were related inversely to marital satisfaction (for a related analysis, see Lavin, 1987).

A second reason for examining higher-order attribution constructs rather than individual dimensions is a practical one and applies to the coding of spouses' open-ended responses to relationship events. Because spouses are unlikely to provide information relevant to all or even most of the attribution dimensions of interest in an open-ended response format, trained coders are instructed to assign responses to broadly inclusive categories. In studies conducted by Holtzworth-Munroe and Jacobson (1985) and Camper et al. (1988), coders were taught to designate as distress maintaining those attributions for negative partner behavior "that explained the behavior as being due to the partner or his or her personality traits, voluntary, intentional or done with negative intent, stable, and global," whereas relationship-enhancing attributions for negative partner behaviors were those "that explained the behavior as being due to outside circumstances or to the partner's temporary state, in-

\footnotetext{
${ }^{4}$ The stability dimension bears closer attention in light of recent speculation that distressed spouses from the community are likely to see their problems as more stable, and hence do not seek counseling, than are either couples seeking counseling or nondistressed community spouses (Camper, Jacobson, Holtzworth-Munroe, \& Schmaling, 1988; Fincham, 1985a). Although caution is necessary in interpreting null effects from comparisons of the latter two groups as support for this proposition, existing data are consistent with the hypothesis that distressed community spouses are particularly inclined to view the causes of their difficulties as stable over time.
} 
voluntary, unintentional or done with positive intent, unstable, and specific" (Holtzworth-Munroe \& Jacobson, 1985, p. 1403). Corresponding definitions for attributions in response to positive partner behaviors were also provided.

Holtzworth-Munroe and Jacobson (1985) found that, for positive and negative partner behaviors, nondistressed spouses were more likely than distressed spouses to make relationshipenhancing attributions, whereas distressed spouses were more likely than nondistressed spouses to make distress-maintaining attributions. In general, these group effects did not interact with valence of partner behavior (see Table 2). In a subsequent investigation of positive and negative partner behaviors derived from videotaped marital interactions, Camper et al. (1988) failed to replicate these effects, a result they ascribed to having examined only two behaviors per respondent.

\section{Summary}

The data reviewed here support the conclusion that an association exists between marital satisfaction and the nature of attributions. Although the association appears to vary with such factors as the valence of the event being explained and the attribution dimension under consideration, it is noteworthy that few studies reported results directly opposite to those predicted. Finally, the association between marital satisfaction and attributions assessed with individual attribution dimensions is corroborated with cross-dimension attribution indices.

\section{Critique}

\section{Rival Hypotheses}

Independent assessment of attributions and marital satisfaction. A basic assumption in demonstrating an association between attributions and marital satisfaction is that the two constructs can be assessed independently. The possibility that this assumption is untenable for these and other constructs assessed via self-report in the study of marriage is implied by Gottman and Levenson's $(1984$, p. 70$)$ observation that "if a couple is unhappy, they will agree that almost any dimension of marriage that could be negative is in fact negative." This suggests that, because of common method variance and spouses' desire to present themselves in a consistent manner across questionnaires, the reported association between attributions and marital satisfaction is overestimated or spurious.

The accuracy of this argument can be evaluated by examining the results of studies in which common method variance is nonexistent or minimized. Holtzworth-Munroe and Jacobson (1985) found that attributions coded from open-ended responses to partner behavior were related to marital satisfaction, as distressed spouses made more distress-maintaining attributions and fewer relationship-enhancing attributions than did nondistressed spouses. Further evidence against the position that the association between attributions and marital satisfaction is spurious comes from the general pattern observed among the results of studies in Table 2; a much stronger and more consistent set of results might be expected if common method variance were exerting a major impact on the attribution-satisfaction relation. For example, on the basis of Gottman and Levenson's (1984) position, strong results for judgments of blame would be particularly likely, yet only three of eight studies reported full support for an association between this dimension and marital satisfaction. In sum, the weight of evidence appears to argue against the view that the association between attributions and marital satisfaction is an artifact of common method variance. It is difficult to rule out the influence of this factor entirely, however, and efforts should be made to minimize this source of contamination in future research.

A second issue that arises in evaluating the extent to which attributions and marital satisfaction are independently assessed concerns the items that are used to operationally define each construct. In particular, the association between attributions and marital satisfaction may be spurious if the items used to assess these constructs overlap in their content. Inspection of the items on standard measures of marital satisfaction (e.g., Dyadic Adjustment Scale; Spanier, 1976) raises the possibility that the strong effects found on the specific versus global dimension may in part be related to overlapping item content. In addition to global, evaluative questions concerning the extent to which spouses are dissatisfied versus satisfied in their marriage, these inventories include several questions regarding the extent to which spouses agree versus disagree about various marital issues (e.g., sexual relations, friends, in-laws).

Thus, because extreme satisfaction scores will be related to a tendency to report considerable agreement or disagreement across several marital domains, it might be expected that responses to marital satisfaction inventories are related to a tendency to see causes of events as operating across few versus many situations in the marriage. Both assessments involve perceptions of the degree to which events occur across many areas of the relationship. In particular, because marital dissatisfaction has been defined in part as a tendency to view negative events as happening in a number of relationship domains, it may be reasonable to expect that, when presented with a marital difficulty and asked to rate the extent to which the cause of this problem operates in few versus many areas of the marriage, the dissatisfied spouse will tend to report that the cause operates in many areas of the marriage. The satisfied spouse, characterized by a tendency to view negative events as occurring in few relationship domains, will tend to report that the cause operates in few areas of the marriage.

In evaluating this proposal, it would be informative to examine corresponding effects found with nonstandard measures of marital satisfaction. Unfortunately, the six studies using a nonstandard measure of marital satisfaction tended to assess only the locus dimension (see Table 1). In the one study among these that did report data for the specific versus global dimension (Baucom, Bell, \& Duhe, 1982, Study 2), the expected association was found between daily satisfaction scores and specific versus global attributions; lower satisfaction scores were related to a tendency to attribute positive events to specific factors and negative events to global factors.

Existing data suggest that the association between marital satisfaction and the specific versus global dimension is not an artifact, yet the possibility cannot be ruled out that effects involving this and perhaps other dimensions are unduly inflated because of item content that overlaps with measures of marital satisfaction. A strategy for resolving this ambiguity is to refine the construct of marital satisfaction by equating it solely with individu- 
als' global, evaluative judgments of their marital happiness (e.g., Fincham \& Bradbury, 1987a; Norton, 1983).

The role of depression. A second rival hypothesis is that attributions and marital satisfaction are associated because both constructs covary with depression (for reviews, see Gotlib \& Hooley, 1988; Robins, 1988; and Sweeney, Anderson, \& Bailey, 1986). That is, it could be argued that attributional differences arise in marriage not because of variance in marital satisfaction but because of variance in depression.

Despite the fact that the study of attributions in marriage was stimulated in part by the study of attributions in depression (e.g., see Baucom et al., 1982; Fincham \& Bradbury, in press), only recently have data appeared with which to examine this alternate hypothesis (cf. Baucom et al., 1982, Study 1; Fincham \& O'Leary, 1983). Specifically, Fincham, Beach, and Bradbury (in press) conducted two studies in which wives were asked to complete a measure of marital satisfaction and to indicate the extent to which six hypothetical partner behaviors were intentional, selfishly motivated, and worthy of blame. In the first study, depression was assessed via self-report in a community sample. In the second study, structured diagnostic interviews were used to select wives who met Diagnostic and Statistical Manual of Mental Disorders, third edition (American Psychiatric Association, 1980), criteria for major depression. This study included groups of depressed and distressed wives, nondepressed and distressed wives, and nondepressed and happily married wives. As expected, depression and satisfaction were inversely related, yet no support for the rival hypothesis was found in either study. Attributions accounted for variance in satisfaction even when levels of depression were held constant statistically, and attributions of depressed and nondepressed wives who were maritally distressed did not differ; both of these groups did differ, however, from happily married wives.

In short, it appears that depression does not mediate the association between attributions and marital satisfaction. Further research on this issue should use both husbands and wives as subjects and should involve ratings of other attribution dimensions. It is particularly important to investigate the locus dimension, as marital researchers typically predict that, in distressed marriages, negative events will be attributed to the partner, whereas the learned helplessness theory of depression (Abramson, Seligman, \& Teasdale, 1978) would predict that negative events will be attributed to oneself. This observation suggests that the interplay among attributions, satisfaction, and depression may not be straightforward and that depression should be viewed as an important factor in developing a comprehensive model of marriage rather than as solely a source of extraneous variance.

The accuracy of attributions. A third rival interpretation for the association between attributions and satisfaction is that, rather than reflecting a truly psychological phenomenon, the attributions made by distressed and nondistressed spouses are simply accurate perceptions for the events they experience. For example, distressed spouses are likely to encounter high rates of negative partner behavior, and it may be accurate to infer that the causes of such behaviors are in fact located in the spouse and are stable and globally influential in the marriage.

Although this viewpoint seems plausible, the question of how to assess the accuracy of attributions in marriage is problematic. Attributional accuracy requires the existence of a norma- tive model, yet there is no such model for marital attributions. Thus, there is no criterion against which observed attributions can be judged. Funder (1987), however, recommended two pragmatic standards for determining the accuracy of social judgments. The first, interobserver agreement, is difficult to apply to marital attributions. For a given behavior by the husband, a wife and another observer may make different attributions as a function of their prior experiences with the husband, the hedonic relevance of the behavior, and its implications for future interaction; these variables are known to influence attributions (e.g., Knight \& Vallacher, 1981; Regan \& Totten, 1975). Despite a lack of agreement between observers, the two attributions are equally valid, and it would be inappropriate to label either of them as inaccurate. According to Funder's second standard, a social judgment is accurate if it allows prediction of behavior. To the extent that the issue of accuracy remains applicable to marital attributions, it is noteworthy that attributions have been found to predict the attributor's behavior in marital interaction (see Attributions and Behavior section).

The accuracy position is weakened further by the fact that satisfied and dissatisfied spouses are found to make different attributions when responding to identical, hypothetical stimuli (e.g., Baucom, Sayers, \& Duhe, 1989). Moreover, attributions made for hypothetical stimuli and stimuli selected uniquely for each spouse are equally predictive of marital satisfaction (Fincham \& Beach, 1988), and values of coefficient alpha derived from combining attribution responses to both types of stimuli are high (Fincham \& Bradbury, 1987c). Although it could be maintained that spouses transform the hypothetical stimuli in a way that makes them unique to their marriage, this implies nonetheless that a psychological process is in fact at work and that attributions do not simply mirror an external "reality." To our knowledge, no research has examined this issue directly, and a number of considerations relevant to its resolution are discussed later in this article (see Attributions and Primary Processing section).

In sum, it is not clear that attributions in marriage can be classified as accurate or inaccurate. It is clear, however, that attributional differences between distressed and nondistressed spouses do not result from differences in stimulus events because they emerge even when standard stimuli are used.

\section{Delineating the Domain of Attributions in Marriage}

Because an understanding of a construct requires clear definition of the class of phenomena denoted by that construct, a necessary task for advancing research on attributions in marriage is the delineation of the conceptual domain to which the term attribution applies. Indeed, Fincham (1985b, p. 205) maintained that this issue "constitutes the single most significant barrier to progress" in the study of marital attributions. Although there appears to be consensus that an attribution is an explanation given for an event (e.g., Arias \& Beach, 1987; Baucom, 1987; Berley \& Jacobson, 1984; Doherty, 1981a, 1981b; Fincham, 1983; Sillars, 1985), little explicit attention has been devoted to specifying the target of inquiry more precisely. Support for this contention is found in Table 1. Although all of these studies claim to examine attributions, the fact that some do so with as few as one dimension, whereas others do so with eight dimensions, suggests that the basic features of attri- 
butions have not yet been agreed on. This is perhaps not surprising, however, as controversies over conceptualization and measurement of attributions are common in the basic social psychological literature (e.g., D. Locke \& Pennington, 1982; Russell, McAuley, \& Tarico, 1987; Shaver, 1981).

In view of the importance of this issue, in this section we identify three adverse consequences of the failure to specify the conceptual domain of attributions in marriage adequately, and we draw on relevant work in social psychology to suggest how basic misunderstandings can be clarified. The three issues that are identified, the studies used to illustrate them, and the suggestions offered are not intended to be exhaustive but are likely to be heuristic in establishing a stronger foundation for research in this domain.

Lack of attention to basic dimensions of causal attribution. A lack of agreement concerning the dimensions necessary to characterize an explanation has led to studies of attribution that have little to do with explanations for events (e.g., the descriptive trait attributions studied by Fichten, 1984; likelihood of marital success studied by Schriber, Larwood, \& Peterson, 1985). More common, however, is the proposal of dimensions that overlap with each other conceptually. For example, a number of studies assess the extent to which a marital event is due to the partner's state versus disposition (see Table 2), a dimension that confounds the information available from the locus dimension with that from the unstable versus stable dimension.

Considering first the case of causal attributions, or explanations for the occurrence of an event, it can be argued that a resolution to this confusion would come from defining an irreducible and finite set of dimensions on which all causes could be judged. Weiner's (1986) recent review of the large body of research and theory devoted to this task led him to conclude that there is "a pleasing simplicity to attributional structure ... a few basic dimensions underlie the organization of [causal] explanation" (p. 44). In particular, it appears that a taxonomy of causal attributions comprises the locus, stability, and control dimensions such that a cause is judged according to where it is located, the extent to which it fluctuates or remains constant, and the degree to which it is controllable or uncontrollable.

Weiner (1986; see also Weiner, 1985a) also acknowledged the possibility that a comprehensive causal taxonomy may require inclusion of the specific versus global and unintentional versus intentional dimensions. Although the specific versus global dimension has not emerged in empirical analyses of the dimensions underlying perceived causes (e.g., Meyer, 1980; Michela, Peplau, \& Weeks, 1982; Passer, Kelley, \& Michela, 1978; Wimer \& Kelley, 1982), this may be a consequence of using undergraduate subjects and studying content areas (e.g., success and failure in the achievement domain) that are relatively circumscribed. Marriage is characterized by interpersonal exchange across many settings, however, and a complete assessment of causal attributions in this domain is likely to include judgments of the extent to which a cause operates in few versus many marital situations (for a similar argument in the depression literature, see Abramson et al., 1978).

The second additional dimension considered by Weiner (1986), unintentional versus intentional, is more difficult to defend as a dimension of perceived causality. Unlike the dimensions of locus, stability, controllability, and globality, intent is not a property of a cause but is instead a characteristic ascribed to an individual who brings about an event. As a consequence, Weiner assigned the intent dimension a minor role in his causal taxonomy. It is important to note, however, that the emphasis in Weiner's work is on the dimensions of causal attribution. This contrasts with a broader focus in the marital domain that also includes responsibility attributions, which are judgments that presuppose a causal attribution and concern an individual's accountability or answerability for some event (see Fincham \& Bradbury, 1988; Fincham \& Bradbury, in press). Because intent is a central dimension in the determination of responsibility, we argue that it should not be viewed as a minor element of causal attribution but as a basic element of responsibility attribution. Additional dimensions that combine with intent to define the domain of responsibility attribution, and further distinctions among types of attributions, are considered in detail at a later point in this section.

To summarize, it appears that the dimensions of locus, stability, control, and globality are necessary and sufficient for assessing causal attributions in marriage. A task for future research is to determine whether the conceptual distinctions among these dimensions are empirically defensible. To the extent that these dimensions intercorrelate highly, their status as distinct facets of causal attribution may be unjustified. However, it is important to separate conceptual and empirical levels of discourse as, for example, a conceptual distinction between the stability and globality dimensions could be defended in the face of their high empirical association if the dimensions were found to correlate differently with some other construct (e.g., help-seeking).

The foregoing proposal leads to several observations about how causal attributions have been studied in marriage. First, it would appear that the use of composite attribution indices may be premature. Because they involve collapsing over several dimensions to produce a single measure, composite indices may conceal important information and thus eliminate the opportunity to learn about distinctions among attribution dimensions (cf. Baucom, Sayers, \& Duhe, 1989). Second, a number of investigations purport to examine causal attributions in marriage yet also include attribution dimensions that do not pertain to causes of events (e.g., attitude; see Table 2). This further underscores the lack of conceptual specification noted earlier and argues for the establishment of closer ties between measurement decisions and guiding theory. Third, despite its fundamental role in perceived causality (e.g., Weiner, 1986), little attention has been given to the control dimension (cf. Fincham, Bradbury, \& Grych, in press). That this dimension has been examined in only three studies, with mixed results (see Table 3), suggests an obvious area for future study.

Lack of attention to measurement of causal attribution dimensions. Even if a fundamental set of causal dimensions were to be widely accepted, issues concerning how those dimensions are best measured would need to be addressed. Several sources of evidence point to a lack of agreement over how to measure attribution dimensions.

It can be seen in Table 2 that dimensions of causal attribution have at times been operationally defined in such a way that the cause of the event is not even the focus of the question. For example, the stability dimension, which refers to the extent to which an event's cause fluctuates versus remains constant, was assessed by Holtzworth-Munroe and Jacobson (1985, p. 1402) 
in terms of "whether the behavior would occur frequently in the future." Because this question requests a spouse to make a prediction about the likelihood of a behavior's occurring in the future, little direct information about the stability of the cause is provided. That is, a behavior can occur frequently (e.g., "spouse kissed me") yet have an unstable cause ("He was in a good mood"), and a behavior can occur infrequently ("spouse nagged me") and have a stable cause ("He's an irritable person"). This problem can be circumvented by assessing the cooccurrence of the event and its cause, independent of event frequency, by asking a question such as "When this event occurs in the future, to what extent will the cause again be present?" The stability of the cause for the specified event can be inferred from higher levels of endorsement on this question.

Even when the cause of an event is the focus of the question, however, there is at times a lack of agreement in how the dimension should be assessed. For example, lack of consensus in measurement is particularly apparent on the locus dimension. As shown in Table 2, a number of studies have assessed this dimension with a single item with different causal loci as endpoints. An assumption of this approach, known as the hydraulic assumption, is that the causal loci serving as endpoints are inversely correlated such that a higher endorsement of one endpoint necessarily implies lower endorsement of the other. Because marital (Fincham, 1985a) and nonmarital (Solomon, 1978; Taylor \& Koivumaki, 1976; F. D. Miller, Smith, \& Uleman, 1981) data yield "little evidence that subjects perceive causality in this fashion" (Taylor \& Koivumaki, 1976, p. 408), some marital investigators have instead assessed the various causal loci with separate questions using a low versus high response scale (see Table 2).

This change was accompanied by a second development in the assessment of causal locus, involving the identification of a causal locus that is particularly salient within close relationships. Following the rationale that social psychological analyses of attribution are not entirely adequate for the study of marriage because they emphasize the perspectives of actors and observers rather than their relationship, Newman (1981a, 1981b; see also Howe, 1987; Kelley, 1979) proposed that the study of marital attributions should include an interpersonal causal locus to capture perceptions of self in regard to partner ("I treat her with respect") and partner in regard to self ("She understands me"). Along with the loci of self, partner, and outside circumstances, the interpersonal locus (e.g., a low versus high rating of the extent to which the cause of an event rests within the relationship) has since been assessed with mixed results in recent studies comparing distressed and nondistressed spouses (Camper et al., 1988; Fincham, 1985a).

Despite these advances, it can nevertheless be argued that the locus dimension still fails to reflect the way in which individuals perceive causality in marriage. The inadequacy of the present approach appears to stem not from the questions asked but from statistical analyses that treat the separate locus questions independently. Not unlike the "hydraulic" item noted earlier, this approach may not parallel the process by which spouses actually make their locus judgments. Current analytic strategies overlook the fact that a wife, for example, may rate herself 2 scale points higher than she rates both her husband and her relationship as the causal locus for a negative event, a comparison that is likely to be quite pertinent in guiding her response. It is recommended that in future research the separate locus responses be considered relative to one another, and that emphasis be placed on the pattern of responses across dimensions rather on the responses made on any one locus dimension.

The importance of attending more closely to the locus dimension is emphasized by the striking discrepancy between the prominent role accorded to this dimension in theoretical accounts of attributions in marriage (see Doherty, 1981a; Fincham \& Bradbury, 1987b; Hotaling, 1980) and the inconsistent results that have been reported. However, applying this recommendation to those studies reporting distressed and nondistressed spouses' mean responses on several individual locus questions reveals an interesting and more consistent set of findings. Starting with data reported by Fincham, Beach, and Baucom (1987, Study 1), it can be noted that even though the partner is typically rated higher than oneself as a causal agent for negative events, distressed spouses rate outside circumstances as being least important in causing the event, whereas nondistressed spouses rate outside circumstances as being most important.

Similarly, the means reported by Camper et al. (1988) indicate that distressed spouses tend to rate the relationship higher than themselves as a cause of negative events, whereas the opposite pattern is found for nondistressed spouses. As a final example, Fincham (1985a) reported that among distressed spouses the partner is typically rated more highly than oneself as the causal locus for marital problems, whereas nondistressed spouses tend to rate themselves higher than their partner. Although these observations must be interpreted with caution, they are consistent with the hypothesized relation between causal locus and marital satisfaction, namely, that nondistressed spouses make relatively more benign attributions than do their distressed counterparts. Further examination of response patterns on the locus dimensions therefore appears justified.

Lack of attention to types of attribution. A third consequence of insufficient specification of the domain of attributions in marriage is a lack of attention to types of attributions. Following the rationale that it is "profitable to see explanations as more than perceptions of causes" (Antaki \& Fielding, 1981, p. 29), some social psychologists have distinguished causal attributions from attributions of responsibility and, furthermore, have distinguished both of these from attributions of blame (see Antaki \& Fielding, 1981; Brewin \& Antaki, 1987; Fincham \& Jaspars, 1980; Forsyth, 1980; Hamilton, 1980; Shaver, 1985; Shaver \& Drown, 1986; Shultz \& Schleifer, 1983). Thus, whereas causal attribution pertains to the factors that produce an event, attribution of responsibility involves a judgment regarding an individual's accountability for the event and attribution of blame is an evaluative judgment concerning the implicated individual's liability for censure. The distinction between responsibility and blame is a subtle one in that both judgments rest on the same set of underlying dimensions (K. G. Shaver, personal communication, July 1987); this distinction therefore warrants further elaboration. ${ }^{5}$

\footnotetext{
${ }^{5}$ The term responsibility can be used with a variety of adjectives that change its meaning (e.g., role responsibility, capacity responsibility, legal responsibility). Our use of the term is restricted to liability responsibility (for further discussion, see Hart, 1968).
} 
Two features have been emphasized in distinguishing responsibility from blame. First, it is hypothesized that the two judgments differ in their relation to the account given for a behavior (Shaver, 1985; Shaver \& Drown, 1986). Holding someone responsible for an event is tantamount to a charge that calls for rebuttal and usually leads the accused person to offer an account for his or her behavior. According to Shaver (1985), responsibility is a judgment made before an account is given, whereas blame is assigned after the account is given and evaluated. From this perspective, blame cannot be determined veridically without knowing the person's account for his or her behavior. In marriage, however, spouses readily assign blame in the absence of input from the partner and without the apparent need for such input. It is therefore unlikely that this is a relevant distinguishing feature between responsibility and blame in marriage.

A second distinguishing feature that has been emphasized concerns the nature of responsibility and blame judgments. Unlike responsibility, blame is primarily an evaluative judgment that involves fault and liability for censure. Thus, an attributor may hold someone responsible for an event but not blame him or her for it. This feature does appear to be relevant to marriage, although the extent to which spouses actually make judgments that are not evaluative remains to be determined. In sum, the basis for distinguishing responsibility from blame in marriage rests on the extent to which the judgment is an evaluative one concerning fault and liability for censure.

To determine the usefulness, if any, of distinguishing attributions of responsibility and blame from each other and from attributions of cause, a necessary first step is to consider the manner in which responsibility and blame might be measured. Basic research on attribution (see Antaki \& Fielding, 1981; Brewin \& Antaki, 1987; Fincham \& Jaspars, 1980; Shaver, 1985; Shaver \& Drown, 1986; Shultz \& Schleifer, 1983) indicates that measurement of responsibility and blame should include consideration of a number of underlying dimensions. In particular, judgments of responsibility and blame rest on the extent to which a spouse is judged to have acted (a) intentionally rather than unintentionally; (b) with negative, selfish, or harmful motivation rather than with positive, selfless, or harmless motivation; (c) voluntarily, by free choice, and in the absence of outside coercion rather than involuntarily, not by free choice, and in the presence of outside coercion; (d) with foresight or awareness of the consequences of his or her actions rather than without such foresight or awareness; (e) with appreciation of the wrongfulness of his or her action rather than without such appreciation; and (f) with the capacity to have done otherwise rather than without such a capacity. In addition, it is necessary to determine the extent to which a spouse considers his or her partner to be at fault and liable for censure in order to distinguish a responsibility judgment from one of blame.

Following this brief introduction, we argue that attributions of cause, responsibility, and blame may be distinct but related phenomena in marriage and, hence, are worthy of systematic attention. As an illustration of these distinctions, a husband may criticize his wife for neglecting to pick up their tickets for an upcoming vacation. Her causal attribution for his complaint may be that increased pressure at work has led him to be irritable lately. She may hold him responsible for his behavior as she expects that he will not bring home his problems from work.
On learning from him that he did not intend to criticize her and that he was not aware of the impact it would have on her, she may not blame him for what he did (e.g., "It's not really his fault"). From this illustration it can be inferred that not only are the three sorts of attributions likely to be distinct, but they are also likely to unfold in an orderly sequence. This ordering is known as the entailment or presupposition model (see Fincham \& Jaspars, 1980; Shultz \& Schleifer, 1983), such that the assignment of blame presupposes a judgment of responsibility that, in turn, presupposes an attribution of cause. Moreover, questions regarding responsibility typically arise only when an individual has caused some event, and judgments of blame typically arise only when an individual is deemed responsible for it. (For related discussion, see Attributions as Behaviors section.)

An obvious implication of this model is that measures of cause, responsibility, and blame will be related empirically. This proposition has received support from investigations in social psychology, yet these studies also leave little doubt that the three types of attribution should be retained as separate constructs rather than being combined simply because of their association (e.g., Critchlow, 1985; Fincham \& Roberts, 1985; M. D. Harvey \& Rule, 1978; Shultz, Schleifer, \& Altman, 1981). Although their extension to research on marriage may yield a different outcome, these distinctions among types of attributions are offered here in the belief that a demonstration of their inadequacy is likely to be more fruitful than the uncritical assumption of their homogeneity.

Distinguishing among these three types of attributions makes salient several inconsistencies and implicit assumptions of prior research on marital attributions. Four issues are highlighted here as they provide an immediate focus for enhancing subsequent work in this domain. First, although attributions of cause are likely to influence attributions of blame, the two cannot be equated. This position contrasts with that found in most of the literature. In a recent study, for example, attributions for marital events, which were made on a single-item scale ranging from extreme situational to extreme dispositional, were interpreted to indicate that "people in high-stress marriages gave their spouses . . . more blame for their negative interpersonal behaviors than people in low-stress marriages" (Kyle \& Falbo, 1985, p. 349; emphasis added). Only when blame is measured directly is such an inference permissible. Second, similar interpretive rigor is needed to maintain the distinction between attributions of cause and attributions of responsibility. The failure to do so is evident in studies where judgments of intent and volition are identified as causal rather than responsibility attributions (e.g., Camper et al., 1988).

Third, we have argued for a distinction between attributions of blame and attributions of responsibility. In a series of studies, these two judgments have been combined and referred to simply as attributions of responsibility (Fincham \& Beach, 1988; Fincham, Beach, \& Baucom, 1987, Study 2; Fincham, Beach, \& Nelson, 1987; Fincham \& Bradbury, 1987c). This practice cannot be justified on the basis of the high intercorrelations found among these judgments (e.g., Fincham, Beach, \& Nelson, 1987) because any differences among the correlates of the constructs are likely to be overlooked. (Although our analysis suggests that it is inaccurate to consider judgments of blame as responsibility attributions, we shall continue to use this label when referring to the studies that do so in order to be consistent 
with the manner in which the data were originally presented.) Finally, existing studies of responsibility attributions are limited in the number of dimensions they include. Because the majority of the dimensions relevant to responsibility and blame have not been assessed, the role of these attributions in marital dysfunction may be underestimated.

\section{Conclusion}

In their discussion of the literature on marital attributions, J. S. Thompson and Snyder (1986) concluded that "research has supported a strong association between attributional processes and relationship satisfaction" (p. 135; see also Arias \& Beach, 1987; Holtzworth-Munroe \& Jacobson, 1988a). Although the research that has since accumulated is consistent with this conclusion, a note of caution is necessary insofar as overly enthusiastic claims may actually hinder a thorough understanding of the apparent relation between attributions and satisfaction. To further an understanding of this relation, greater attention needs to be devoted to (a) independent assessment of these two constructs, (b) the possible role of depression in the association between attributions and satisfaction, (c) the degree to which attributions can be viewed as accurate perceptions of marital events, (d) the different types of attributions (i.e., attributions of cause, responsibility, and blame) and their underlying dimensions, and (e) more adequate measurement of attributions.

\section{Is There a Causal Association Between Attributions and Marital Satisfaction?}

\section{Review}

Although the research examined in the previous section indicates that concurrent measures of attributions and marital satisfaction covary reliably, attention must shift to the potential causal association between these variables if interest in marital attributions is to be sustained (J. M. Olson \& Ross, 1985). Two opposing positions have been taken on this issue. First, Heider's (1958) observations, noted earlier, suggest that the affective tone of interpersonal relationships exerts a causal influence on the attributions that occur. The widespread assumption among marital researchers, in contrast, is that attributions maintain and perhaps initiate marital dissatisfaction (see Arias \& Beach, 1987; Baucom, 1987; Berley \& Jacobson, 1984; Bradbury \& Fincham, 1987; Doherty, 1981a; Fincham, 1985b; Hotaling, $1980 ;$ J. S. Thompson \& Snyder, 1986). Experimental and longitudinal research that address these two possibilities, as well as the third possibility that satisfaction and attributions are reciprocally determined, is reviewed in the following two sections. In discussing this research we occasionally use the term relationship quality to refer to the general class of dependent variables involving measures of love, happiness, and satisfaction. This does not imply that these variables reflect identical phenomena; however, they do share the common feature of an affective evaluation of a relationship or partner.

\section{Experimental Approach}

Laboratory research. Seligman, Fazio, and Zanna (1980) hypothesized that manipulation of an individual's explanation for being in a dating relationship would influence the degree of love held for his or her partner. Specifically, subjects for whom extrinsic reasons for being in the relationship were made salient (e.g., "I go out with my girlfriend because she has a car") were expected to report less love for their partner than subjects for whom intrinsic reasons were made salient (e.g., "I go out with my boyfriend because we always have a good time together"). The salience of these reasons was manipulated by instructing subjects to rank-order by importance a series of extrinsic or intrinsic reasons and to answer open-ended questions favoring extrinsic or intrinsic responses.

Consistent with hypotheses, extrinsic-set subjects reported less love for their partner on Rubin's (1973) Love Scale following the salience manipulation than did the intrinsic-set and control (no-set) subjects. Extrinsic-set subjects also reported less likelihood that they would marry their partner than did subjects in the other groups. Differences were not found, however, when groups were compared on a single item assessing global love, Rubin's (1973) Liking Scale, and a single item assessing global liking.

Clinical outcome research. The assumption noted earlier, that attributions at least perpetuate and possibly cause marital dissatisfaction, is also evident in clinical writings on this subject (see Bagarozzi \& Giddings, 1983; Baucom, 1981; Bennun, 1986; Epstein, 1982; Fincham, 1983; Holtzworth-Munroe \& Jacobson, 1988a; Jacobson, 1984; Jacobson \& Margolin, 1979; Revenstorf, 1984; Schindler \& Vollmer, 1984; Weiss, 1980; Wright \& Fichten, 1976). Initial data relevant to this assumption come from three treatment outcome studies that include a cognitively oriented intervention.

Margolin and Weiss (1978) assigned distressed couples to either a control group receiving nonspecific, supportive counseling or a treatment condition designed to (a) modify skills in communication or (b) modify communication skills in combination with "cognitive restructuring." The purpose of the latter intervention was to belp spouses "to abandon blaming attributions, to accept greater personal responsibility for relationship failure, and to be more accepting of their partners' positive efforts" (Margolin \& Weiss, 1978, p. 1485). Interventions were implemented in two 2-hr sessions by paraprofessional counselors, and preintervention and postintervention evaluations were conducted to assess couples' marital satisfaction, overt communication behaviors, and self-reported daily events occurring in the home.

Negative communication behaviors and negative daily events decreased for all groups, yet the cognitive restructuring group was found to have a higher mean marital satisfaction score than the other two groups at the end of treatment. The cognitive restructuring group was also superior with regard to increases in positive communication behaviors and positive daily events over the course of treatment. These data offer support for a cognitive approach to marital therapy and suggest that changes in attributions may play a prominent role in modifying marital satisfaction and behavior. Nevertheless, because attributions were not actually assessed, it is difficult to determine whether increases in satisfaction were due to changes in attributions or to some other factor that changed as a result of the intervention.

A second study, conducted by Epstein, Pretzer, and Fleming (1982), compared a cognitive intervention, designed to change dysfunctional thoughts and attributions for the causes of mari- 
tal problems, with a communication training intervention in eight sessions of group marital therapy. In particular, two sessions of the cognitive intervention stressed the need for spouses to identify many possible causes for their problems, to make specific rather than global attributions, and to explore which of the causes of problems might be changed.

Results indicated that spouses in the group receiving the cognitive intervention were less likely after treatment to attribute their marital problems to the partner's malicious intent. In contrast, the two groups did not differ in marital satisfaction at the end of treatment and neither group increased significantly in satisfaction over the course of treatment. Unfortunately, these data are subject to a number of methodological shortcomings (e.g., nonindependent observations, inflated Type I error rate, small samples) and should therefore be viewed with caution until replicated.

Finally, in a study by Baucom and Lester (1986), distressed couples were either assigned to a waiting list control group or received 12 sessions of (a) a skills-oriented intervention designed to improve skills in communication and problem-solving or (b) a cognitive restructuring intervention designed to change dysfunctional attributions and expectations, followed by an abbreviated version of the skills-oriented intervention.

Relative to the control condition, satisfaction was found to increase significantly in the two treatment conditions. However, comparison of the two treatment groups following intervention revealed no differences in satisfaction or dysfunctional expectations. Although the failure to assess attributions leaves open the question of whether any change in attributions actually occurred (or whether it occurred in both groups), these data lend no support to the causal impact of attributions on satisfaction. The attempt to modify attributions and expectations, when combined with an intervention designed to alleviate skill defcits, was indeed found to increase satisfaction, yet equivalent increases in satisfaction were obtained when skill deficits were the sole focus of treatment.

\section{Longitudinal Approach}

Although longitudinal data cannot be used to infer causality, measurement of variables at two or more points in time can yield findings that are consistent with a causal relation. The first of two longitudinal studies designed to examine the association between attributions and relationship quality is reported by Fletcher, Fincham, Cramer, and Heron (1987). At two times separated by 2 months, 131 students in close relationships answered questions regarding (a) the degree to which they attributed maintenance of the relationship to themselves versus their partner, ${ }^{6}(b)$ the degree to which they attributed maintenance of the relationship to external factors (e.g., car, friends, money), (c) the degree to which they were happy in the relationship, and (d) the degree of love they felt toward their partner. Initial analyses indicated that all measures were relatively stable over the 2month interval.

With Time 1 happiness scores held statistically constant, attributing the maintenance of the relationship equally to oneself and one's partner at Time 1 was related to higher happiness scores at Time 2. The corresponding analysis for the second attribution measure, in which Time 1 attributions of relationship maintenance to external factors were used to predict Time 2 happiness scores, was not significant, and judgments of love at Time 2 were not predictable from either attribution measure at Time 1. Furthermore, all attempts to predict later attributions from earlier reports of happiness of love (with appropriate Time 1 attribution scores held constant) were unsuccessful. Thus, although only one of four analyses revealed a significant longitudinal association between attributions and later relationship quality, the failure to find predictive effects in the opposite direction lends some support to the proposition that attributions exert a causal influence on relationship quality.

In a second longitudinal study, Fincham and Bradbury (1987c) examined the association between attributions and satisfaction in a sample of 34 married couples. At two times separated by 12 months, couples reported their marital satisfaction on the Marital Adjustment Test (H. J. Locke \& Wallace, 1959) and, for each of five negative marital events, rated causes on three dimensions and made three attributions relating to responsibility (see Table 1). One causal and one responsibility attribution index was formed for each subject by adding across relationship events the three causal and the three responsibility judgments. These indices were found to be highly stable over the 12 -month interval.

Stability coefficients for marital satisfaction were high (husbands, $r=.66$; wives, $r=.77$ ), indicating that statistically controlling Time 1 satisfaction scores in predicting Time 2 satisfaction scores would leave little variance in Time 2 satisfaction scores to be predicted by the attribution composites. Nevertheless, with Time 1 satisfaction scores controlled, both Time 1 attribution indices predicted Time 2 satisfaction scores. Although the beta coefficients for wives and husbands for the causal index were similar in magnitude, significant effects on both composites were found only for wives. Thus, wives' relationship distress was greater at Time 2 to the extent that they made unfavorable causal and responsibility attributions for their husband's behavior at Time 1 .

Two additional sets of analyses aid in interpreting these findings. First, all attempts to predict Time 2 attribution indices from Time 1 satisfaction scores (with the appropriate Time 1 attribution index statistically controlled) were unsuccessful. Second, analyses were conducted to determine if prediction of later satisfaction from earlier attributions reflected a more general association between cognitive variables in marriage and marital satisfaction. To test this possibility, the major alternative cognitive variable studied in marriage, unrealistic relationship beliefs (Eidelson \& Epstein, 1982), was assessed at Time 1. Despite a concurrent association, no predictive association emerged between unrealistic relationship beliefs and later satisfaction, after variance due to earlier satisfaction had been taken into account. Overall, the data from this study are consistent with the contention that, at least for wives, attributions for negative relationship events causally influence marital satisfaction rather than vice versa, and that this association does not extend to cognitive variables more generally.

\footnotetext{
${ }^{6}$ The question of which partner contributes more to various relationship activities has been the subject of studies designed to examine the availability heuristic and egocentric biases (e.g., Christensen, Sullaway, \& King, 1983; Fincham \& Bradbury, 1989b; Ross \& Sicoly, 1979; S. C Thompson \& Kelley, 1981). These studies are not discussed here because they do not pertain directly to explanations.
} 


\section{Summary}

The findings of the experimental and longitudinal investigations reviewed here are consistent with the pervasive assumption that attributions exert a causal influence on judgments of relationship quality. Less compelling, in contrast, are the results from clinical outcome studies. These studies yielded a variety of results, a pattern that is likely to reflect the difficulties inherent in extending empirical findings from basic research (e.g., that attributions and marital satisfaction are associated) to complex clinical settings.

\section{Critique}

The foregoing review indicates that the data available for assessing the premise that attributions causally influence marital satisfaction are limited. Although the few data are promising, the need for additional studies that test this premise is especially acute as the prominent role assigned to attributions both in theory and in clinical practice may misrepresent their actual significance in marriage. In the following discussion, we offer a critique of existing research and make several recommendations to facilitate a timely resolution of this issue.

\section{Experimental Approach}

Laboratory research. Two concerns arise in evaluating the results of the Seligman et al. (1980) study. First, because Seligman et al. limited their study to couples who had been dating for less than a year, their data may not be directly relevant to long-term relationships. Attention might be devoted nonetheless to attributions in the transition from dating to engagement; the Seligman et al. data suggest that this transition may be less likely to the extent that salience of extrinsic factors is high. In addition, because they are marked by fluctuations in attitudes and relationship rules, the early months of marriage might be examined to test the hypothesis that distress is more likely among those individuals who attribute their own or their spouses' decision to marry to extrinsic factors (e.g., "He really married me to get away from his family") rather than to intrinsic factors (e.g., "He married me because he loves me").

A second issue to consider is whether the intrinsic-extrinsic distinction is indeed relevant to marriage. It can be seen in Table 2 that this distinction has not been studied in relation to marital satisfaction, a fact that is probably due to a difference in level of analysis: Marital researchers have focused on explanations for why relatively discrete events occur within a continuing relationship, whereas Seligman et al. (1980) have studied explanations for why the relationship itself continues.

Two correlational studies help clarify the relevance of the latter class of attribution for the study of marriage. First, in their study of dating relationships (mean duration $=1.3$ years), Fletcher et al. (1987) found a concurrent (Time 1) association between the extent to which relationship maintenance was attributed to external factors and lower levels of happiness, commitment, and love. These results accord well with Seligman et al.'s (1980) extrinsic set findings. A second study by Rempel, Holmes, and Zanna (1985) raised the possibility that the association between extrinsic attributions and relationship quality is operative in dating but not married couples. Using a sample in which $64 \%$ of the couples were married and the mean relationship duration was 9.1 years, Rempel et al. (1985) failed to replicate this association. Close inspection of the Rempel et al. results also indicates that in longer relationships extrinsic factors play a relatively minor role in relationship involvement as the mean response to items on a scale used to assess extrinsic attributions was approximately 2.6 on a 9 -point scale.

In sum, these studies suggest that in dating relationships, but not in marriage, relationship quality is related inversely to the tendency to attribute relationship maintenance and one's own motivation to extrinsic factors. The nonsignificant effect for married couples and the low level of endorsement for extrinsic items reported by Rempel et al. (1985) appear to justify the lack of attention given to the intrinsic-extrinsic distinction by marital researchers. However, inferences concerning intrinsic and extrinsic motivation for being in a relationship may become important in couples for whom continuation of the marriage is a salient issue (e.g., "We only stay married because of the kids").

Clinical outcome research. The inconsistent results obtained in the clinical outcome studies likely stem, in part, from the incomplete understanding of attributions in marriage that now exists. Nonetheless, careful exploration of marital attributions in clinical settings has the potential to enrich an understanding of attributions in marriage, and three suggestions are offered here to facilitate such exploration.

First, because it is important to show that the intervention influences attributions and that attributional change is accompanied by change in marital satisfaction, it is necessary to measure attributions before and after clinical interventions. It is only when these conditions hold that variation in satisfaction can be examined as an effect of attributions. To date, when interventions emphasizing changes in attributions have been implemented, attributions either have not been assessed at all (Baucom \& Lester, 1986; Margolin \& Weiss, 1978; see also Emmelkamp et al., 1988) or have been assessed along only a few dimensions (Epstein et al., 1982), and no attempt has been made to correlate changes in attributions with changes in marital satisfaction.

Second, it is important to specify more precisely how change in attributions is best achieved in marital therapy. The approach used to date is largely didactic, as couples are taught attribution principles that are then applied to their unique marital difficulties. In systems-oriented family therapy, in contrast, modification of attributions ("reframing"; Minuchin, 1974) plays an important role in therapy, and change is often achieved without discussion of attribution principles. Thus, whether attribution change is best realized by didactic interventions that focus on attribution principles is open to question. In addition, it is useful to question the assumption that attributions comprise merely an additional therapeutic component that can be appended to a standard behavioral intervention. A more effective approach might be to integrate the modification of attributions into the session-by-session examination of marital difficulties (Baucom \& Lester, 1986; Holtzworth-Munroe \& Jacobson, 1988a).

A third avenue for promoting informative clinical outcome research is to incorporate findings from basic research on marital attributions into intervention strategies. For example, whereas some interventions have emphasized causal attributions for marital difficulties (e.g., Baucom \& Lester, 1986; Ep- 
stein et al., 1982), research comparing distressed and nondistressed couples points clearly to the relative importance of attributions of responsibility (e.g., Fincham, Beach, \& Nelson, 1987). Thus, a valuable next step in outcome research will be to examine the usefulness of assessing and modifying additional classes of attribution (see Fincham, 1985b). Support for this proposal comes from the study of Margolin and Weiss (1978); they placed greater emphasis on attributions of responsibility and blame than on causal attributions and obtained the most consistent evidence to date for the impact of cognitive restructuring on marital satisfaction.

In sum, numerous clinical writings have emphasized the importance of modifying attributions in marital therapy. We have argued here that such an approach, in the context of outcome research, can also contribute to an understanding of the causal association between attributions and marital satisfaction. For this potential to be realized fully, however, it is essential that greater attention be devoted to measuring attributions in outcome research, to specifying their role in marital therapy as a direct versus indirect target of change, and to incorporating research findings into treatment strategies.

\section{Longitudinal Approach}

Three observations are pertinent to the longitudinal studies that have been reported. First, recall that the extent to which relationship maintenance was attributed to external factors was not predictive of later relationship quality (Fletcher et al., 1987). This result, combined with the Seligman et al. (1980) finding that increased salience of extrinsic factors decreased judgments of relationship quality, suggests that under controlled conditions attributions of relationship maintenance can have a causal impact on relationship quality but that they may not have such an impact in naturalistic designs or over longer time intervals.

Second, Fincham and Bradbury (1987c) found that a higher level of marital satisfaction at Time 2 was predictable from benign causal and responsibility attributions at Time 1 only for wives. This gender effect was interpreted to mean that wives are more sensitive to issues of intimacy and caring than are husbands (see Rubin, Peplau, \& Hill, 1981). It follows that the Fletcher et al. (1987) findings may be due to a preponderance of female subjects; at Time $1,76 \%$ of their sample were women. ${ }^{7}$

Third, the significance of the two longitudinal studies is underscored by two factors that militate against their obtaining significant effects. In both studies, little Time 2 variance in relationship quality remained after Time 1 variance was controlled, rendering all the more noteworthy the significant prediction of Time 2 relationship quality with Time 1 attribution measures. In addition, neither study examined relationships that were in their initial stages. The significant predictive relation found with these couples is somewhat unexpected in light of speculation (e.g., Newman \& Langer, 1988) that attributions might exert their greatest influence in the formative stages of relationships. These data do not rule out this possibility, but they do suggest that attributions may be significant throughout a relationship.

Although promising, these findings need to be replicated. Future longitudinal studies should (a) examine attributions and relationship quality with different intervals between assess- ments to determine how robust the predictive association is and (b) consider systematically the effects of relationship duration on attributions and relationship quality. In addition, a more thorough appreciation of the interplay of these variables over time will emerge from investigation of (a) larger samples; (b) gender effects and their implications for individuals' sensitivity to relationship function; (c) more than two assessments, so that more complex causal configurations might be explored, and (d) additional constructs that might be generating the relation between attributions and relationship quality.

\section{Conclusion}

Consistent with a pervasive assumption in the marital literature, several studies reported in this section have suggested that attributions may exert a causal influence on judgments of relationship quality. The longitudinal data are inconsistent with the opposite causal effect, yet it seems quite likely that later attributions are, as Heider (1958) observed, at least in part a function of earlier relationship satisfaction. Several recommendations were offered for examining both possibilities. For example, (a) in experimental research, there is a need to study the effects of manipulated attributions on variables in addition to relationship quality and to reconsider the relevance of the intrinsicextrinsic distinction to marriage; (b) in clinical outcome research, where evidence was weakest for a causal association between attributions and relationship quality, it was argued that greater attention be paid to the measurement and conceptualization of attributions, particularly as they might be guided by basic research on marital attributions; and (c) in longitudinal research, we emphasized the need to examine more intervals of varying lengths and to consider the impact of additional variables (e.g., gender) on the attribution-relationship quality association. Finally, it bears noting that the experimental and longitudinal approaches provide different sorts of information-the former indicating what can happen in controlled circumstances, the latter indicating what does happen in the normal course of events - and both are needed to provide a complete portrayal of the causal associations between attributions and relationship quality.

\section{Conceptual Integration and Directions for Future Research}

Having documented the existence and possible causal nature of an empirical association between attributions and marital satisfaction, our next task is to clarify the theoretical relations between attributions and satisfaction and to consider how their association might be better understood. A conceptual analysis of the association between attributions and satisfaction is valuable because it (a) places in broader perspective the data reviewed in the two previous sections, (b) provides a context for research on marital attributions that builds on the basic attribution-satisfaction effect, and (c) points to new directions for research on attributions in marriage.

\footnotetext{
${ }^{7}$ Although gender differences have been found in these and other studies (Doherty, 1982; Fincham \& Bradbury, 1989a; HoltzworthMunroe \& Jacobson, 1985), no clear pattern among these differences is yet evident.
} 


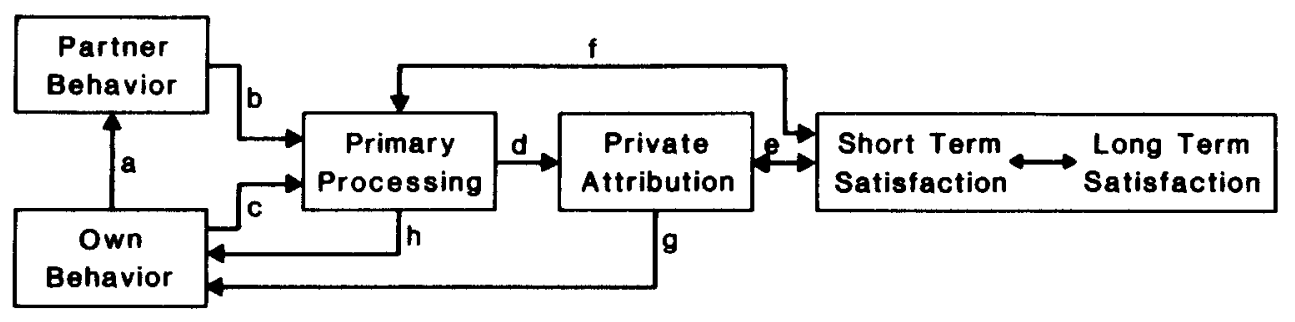

Figure 1. A framework relating attributions, behavior, and marital satisfaction.

A more complete understanding of the relation between attributions and marital satisfaction requires consideration of the behaviors that spouses exhibit when interacting. It is widely assumed that a spouse's attribution for a relationship event influences his or her subsequent behavior (e.g., Arias \& Beach, 1987; Baucom, 1987; Baucom, Epstein, et al., 1989; Berley \& Jacobson, 1984; Doherty, 1981a; Sillars, 1985), and the need to consider the role of attributions in dyadic interaction has been emphasized (e.g., J. M. Olson \& Ross, 1985). Explicit consideration of overt behavior in relation to attributions and marital satisfaction is justified further by its potential to integrate attribution research with the large body of research and theory on behavior in distressed and nondistressed marriages. In view of these considerations, we turn our attention to the theoretical relations among attributions, behavior, and marital satisfaction.

\section{A Framework Relating Attributions, Behavior, and Marital Satisfaction}

Several factors must be examined in a model that integrates attributions, behavior, and satisfaction. First, because many significant events occur in the context of dyadic interaction in marriage (e.g., conflicts), it is necessary to include in such a model the overt behaviors of the husband and the wife rather than those of only one spouse. Second, because it is unlikely that a spouse will make attributions in response to all or even most partner behaviors, allowance should be made for a nonattributional stage of processing during which a spouse attends to and extracts information from a partner behavior. As a function of the outcome of this stage, which we refer to as primary processing, an attribution may or may not occur. In keeping with the focus of most research on marital attributions, our primary emphasis is placed on those attributions that are private and not communicated to the spouse (cf. Attributions as Behaviors section). Third, because it is unlikely that a spouse's attribution for a given partner behavior will have a significant impact on that spouse's long-term marital satisfaction, a distinction must be drawn between transient, statelike short-term satisfaction and stable, traitlike long-term satisfaction. It is expected that short-term satisfaction is in part a consequence of long-term satisfaction and, in reciprocal fashion, that transient feelings of satisfaction accumulated over time can affect long-term satisfaction.

A framework outlining the theoretical relations among these concepts (i.e., husband behavior, wife behavior, primary processing, private attribution, short-term satisfaction, and longterm satisfaction) is shown in Figure 1. The framework is shown in detail for only one spouse, designated arbitrarily as the wife.
The remaining components, which would represent the corresponding primary processing, private attribution, and satisfaction of the husband, have been omitted for simplicity (for related discussion, see Bradbury \& Fincham, 1988b; Fincham \& Bradbury, 1988a, in press).

According to this framework, the husband's behavior is followed by primary processing on the part of the wife (path b), during which she attends to and imbues the behavior with meaning; she may engage in similar processing of her own behavior (path c) that gave rise initially to the husband's response (via path a). To the extent that the wife perceives the husband's behavior to be low in negativity, unexpectedness, and self-relevance, she is likely to respond behaviorally without any further processing (path h). In contrast, if the husband's behavior is perceived to be high on these dimensions, the wife is likely to make an attribution for the behavior (path $d$ ) and then behave in a way that is influenced by this attribution (path g; see Weiner, $1985 \mathrm{~b}$, for review of factors that promote the occurrence of attributions). The outcome of primary processing and the nature of the attributions that occur are expected to influence, and be influenced by, marital satisfaction (paths f and $e$, respectively).

This framework points to important gaps in the research reviewed earlier. It is evident that most prior research has examined path $\mathrm{e}$ in Figure 1, concerning the nature of private attributions and their direct relation to long-term satisfaction. In contrast, the indirect relations between attributions and satisfaction (e.g., path b, d, g, a, b, f; path b, d, g, c, f) have yet to be investigated. In addition, little attention has been devoted to attributions and short-term satisfaction (cf. Baucom et al., 1982), despite the likely possibility that attributions will have a more consistent impact on transient rather than stable feelings about the marriage. Although attributions may have direct consequences for long-term satisfaction, particularly when spouse behaviors are seen as extremely negative, unexpected, and selfrelevant (e.g., an extramarital affair), it is expected that these instances will be relatively rare.

In sum, the framework we have proposed indicates that it is probably insufficient to assume a simple association between attributions and marital satisfaction, insofar as there may be indirect as well as direct relations between these concepts and as marital satisfaction itself can be understood as having both transient and stable components.

\section{Implications of Framework for Future Research}

Although it is useful to outline a model that places existing research into a broader conceptual context, a more valuable function is served when the model identifies topics that have yet 
to be pursued systematically. Five such topics are discussed in the following sections.

\section{Attributions and Behavior}

An important hypothesis derived from Figure 1, and implied specifically by the indirect association posited between attributions and satisfaction, is that the attribution made by a spouse for the partner's behavior will be related to that spouse's subsequent behavior (path $\mathrm{g}$ ). Despite its obvious theoretical significance, few investigations have examined the contribution of attributions to marital behavior (for similar discussions in the social psychological literature, see Eiser, 1983; J. H. Harvey \& Weary, 1984; Kelley \& Michela, 1980). Moreover, of the few marital studies that bear on this hypothesis, most have failed either to sample a wide range of marital satisfaction (Doherty, 1982; see also P. C. Miller, Lefcourt, Holmes, Ware, \& Saleh, 1986) or to provide adequate measures of attributions (Doherty, 1982) or behavior (e.g., self-reported behavioral intentions; Fincham, Beach, \& Nelson, 1987; Fincham \& O'Leary, 1983).

In a study designed to overcome these problems, Bradbury, Fincham, and Beach (1989) correlated the causal and responsibility attributions that spouses made for a major marital problem with the positive and negative behaviors that spouses exhibited in a discussion of this problem. Because an association between attributions and behavior could be expected solely on the basis of their shared variance with marital satisfaction, satisfaction scores were held statistically constant. Consistent with the hypothesis derived from Figure 1, attributions were found to be related to behavior. For example, spouses attributing higher levels of intent to their partner's contribution to the identified problem were observed to exhibit higher rates of negative behavior. Sequential analysis indicated further that the likelihood of a husband's reciprocating his wife's negative behavior correlated positively with the degree to which he viewed her contribution to the problem as intentional; the likelihood of a wife's reciprocating her husband's negative behavior was related positively with the degree to which she viewed his contribution to the problem as selfishly motivated and worthy of blame.

Although promising, this study provides only an incomplete test of the hypothesis under consideration. First, the link between private attributions and behavior in Figure 1 implies a causal effect, which cannot be inferred from the correlational data. Second, because attributions concerned the partner's contributions to the problem and not specific partner behaviors in the interaction, it cannot be determined from these data whether attributions influenced discrete behavioral responses. Finally, this study presupposes that partner behaviors would be viewed by the spouse as negative, unexpected, and self-relevant and that attributions would necessarily follow, thereby circumventing any possible variance in the primary processing stage.

Recognition of these limitations will be useful in future attempts to conduct research addressing the impact of attributions on behavior in marriage. One possibility for providing a more definitive test of this hypothesis would involve an experimental paradigm in which one partner in a couple is instructed covertly to behave in a particular manner (e.g., to say something critical to the spouse), following which the spouse's behavior in an interaction with the partner could be observed (cf. Fincham
\& Bradbury, 1988b; Jacobson, McDonald, Follette, \& Berley, 1985 ). With appropriate control groups and with manipulation checks to determine that an attribution for the event actually occurred and that the partner behavior was in fact attributed to the partner, a significant association between attributions and behavior could be interpreted more confidently as being a causal relation. $^{8}$

A second strategy for testing the hypothesis that attributions influence behavior in marriage entails modification of the talk table, a procedure used to study marital communication (e.g., Gottman et al., 1976). In this procedure, spouses are required to speak one at a time and to rate privately the intended impact of each message they send and the perceived impact of each message that they receive. The discrepancy between ratings of intended impact and perceived impact has been identified as a distinguishing feature of distressed marriages (e.g., Gottman et al., 1976). To test the possibility that attributions are related to behavior in marriage, the talk-table procedure could be modified by requesting spouses to make a responsibility-related attribution following partner behavior (e.g., "To what extent was your partner's message intentionally negative or motivated by selfish concerns?") and then observing the spouse's behavior that immediately followed such ratings. Although not without limitations (e.g., attributions are elicited directly rather than allowed to occur naturally), a modified talk-table study would yield important data that could, in combination with correlational and experimental studies, provide a clear test of the widely held but untested assumption that attributions affect behavior in marriage.

\section{Attributional Style}

In an early article on marital attributions, Fincham and O'Leary (1983) speculated that, rather than being a unique response to a specific partner behavior, spouses' attributions may reflect a general attributional style. In terms of Figure 1, this issue pertains to the covariation between partner behavior and private attributions: A systematic relation between various partner behaviors and attributions for those behaviors would suggest the absence of an attributional style, whereas relative independence between partner behaviors and subsequent attributions (which themselves demonstrate little variance) would support the presence of an attributional style. Figure 1 indicates further, however, that the association between partner behavior and spouse attributions may differ as a function of the spouse's level of marital satisfaction (via paths $e$ and $f$ ). Thus, elaborating on Fincham and O'Leary's speculation, attributional style may be more characteristic of spouses either high or low in marital satisfaction. In view of research showing that distressed spouses exhibit greater rigidity or predictability between their behaviors than do nondistressed spouses (Gottman, 1979), it can be hypothesized that attributional style is more characteristic of unhappy spouses.

Attributional style in marriage has been assumed rather than

\footnotetext{
${ }^{8}$ Such research is problematic, however, because it involves deception. In the event that the benefits of such studies are judged to outweigh the possible risks that may be incurred, it is essential that trained experimenters be used, that debriefing be thorough, and that counseling be readily available to all couples.
} 
demonstrated (e.g., Doherty, 1982), and the issue has yet to receive programmatic attention (a similar assumption is made in the depression literature; see Cutrona, Russell, \& Jones, 1985). Nevertheless, the results of two studies are consistent with the hypothesis that attributional style is indicative of marital distress. First, Baucom et al. (1982, Study 2) found that nondistressed spouses made dysfunctional causal attributions for partner behaviors on those days when they were temporarily dissatisfied with their marriage. In addition to lending credence to the distinction made earlier between short-term and long-term satisfaction, this study suggests that, at least for happily married spouses, attributions are not temporally and situationally consistent but are instead specific responses to discrete events.

This line of research could be extended by including a group of distressed couples and examining the complementary hypothesis that they will offer relatively benign attributions on those days when they are feeling more satisfied with their relationship. Our earlier hypothesis (i.e., that attributional style will be indicative of marital distress) and a second study by Baucom, Sayers, and Duhe (1989) suggest that this complementary hypothesis would be refuted. For each of five causal attribution dimensions (see Table 1), Baucom, Sayers, and Duhe computed for each spouse the degree of variance in the attribution ratings across 24 partner behaviors. In relating these measures to spouses' ratings of long-term satisfaction, it was determined that greater variability in attributions correlated positively with satisfaction; the pattern of results was generally strongest for wives, for negative events, and for the global attribution dimension. These findings were interpreted by Baucom, Sayers, and Duhe to suggest that distressed spouses are particularly likely to use an attributional style when making explanations for partner behavior.

This line of research holds considerable promise for enriching our understanding of attributions in marriage, and at least five issues appear worthy of further inquiry. First, it is difficult to overlook the parallel between Baucom, Sayers, and Duhe's (1989) consistent findings on the globality dimension and the strong performance of this dimension across all of the marital attribution studies (see Table 3 ). There is no a priori reason why results for variability in attributions should mirror those for the nature of attributions, suggesting that it may be important (a) to examine the association between these two ways of analyzing attribution ratings (i.e., variances and means) and (b) to consider their relative contributions to explaining variance in marital satisfaction. In this latter regard, it might be expected that, to the extent that an attributional style reflects the chronic use of mindless, overlearned explanations for negative partner behavior, the relation between satisfaction and the nature of attributions would be stronger among those spouses found to have a more consistent attributional style.

Second, it would be useful to investigate the interpersonal consequences of different attributional styles. One such possibility, that greater degrees of attributional style account for the observed rigidity or predictability between spouse behaviors in distressed marriages, has already been noted. In addition, it might be argued that higher levels of independence between the husband's behavior and the wife's interpretation of that behavior (paths b and d) would lead the wife to behave in ways that cause the husband (via paths $g$ and a) to feel that the wife does not understand him, that he is being treated unfairly, that she is not listening to what he is really saying, or that she is getting upset for no apparent reason. Thus, over the course of time an attributional style could contribute to misunderstandings and marital discord and would lead to the well-known complaints of poor communication that typify couples seeking counseling.

This proposal implies that attributional style causes marital distress, yet the opposite causal relation, or bidirectional causality, is equally plausible. Thus, a third topic for future research is to investigate the longitudinal association between marital satisfaction and variance in attribution responses. Although the Baucom, Sayers, and Duhe (1989) results indicate that relatively invariant attributions for negative as well as positive events relate directly to marital distress, the possibility might be explored that an attributional style for positive events relates to increases in satisfaction, whereas an attributional style for negative events relates to decreases in satisfaction. Longitudinal research could be further enhanced by including samples of engaged or newlywed couples and examining how attributional styles develop and evolve over the course of marriage.

Finally, two implications for subsequent research follow from evaluating Metalsky and Abramson's (1981, p. 38) definition of attributional style as "a tendency to make particular kinds of causal inference, rather than others, across different situations and across time." First, to study the notion of attributional style appropriately, attributions should be assessed at different times as well as in different situations. It may be particularly important for clinical interventions, for example, to determine whether an individual's attributional style exists solely in the context of the marriage or whether it pertains to many of his or her close relationships. Second, because the private attributions depicted in Figure 1 are thought to comprise more than causal inferences, there is a need to extend the study of attributional style to include attributions of responsibility and blame.

\section{Attributions as Behaviors}

The framework outlined in Figure 1 makes a clear distinction between overt behavior and private attributions, yet careful observation of marital interaction reveals that some overt behaviors are themselves attributions. Although private attributions have been the primary focus in the marital literature, overt (i.e., verbalized) attributions have also received some empirical attention.

Holtzworth-Munroe and Jacobson (1988b), for example, conducted a study in which causal attributions were coded from videotaped marital interactions. In evaluating this study it is important to realize that the method used taps a different type of attribution (i.e., attributions as overt behaviors) than that assessed by the self-report ratings reviewed earlier (i.e., private attributions). Recognition of these two types of attribution has a number of implications for future studies and, because research on overt attributions is gaining in popularity (e.g., Bradbury \& Fincham, 1988a; Munton \& Antaki, 1988; Stratton et al., 1986), three such implications are considered.

First, although arguments have been made for the relative importance of overt or public attributions on the basis of their likely impact on the partner (see Holtzworth-Munroe \& Jacobson, 1988b; Kelley, 1977), greater attention might be paid nevertheless to types of attribution and to the process by which private attributions come to be verbalized to the partner (i.e., 
path g). For example, it might be hypothesized that the association between private and public attributions varies as a function of marital satisfaction, such that distressed spouses (and satisfied spouses temporarily dissatisfied with their marriage) might be more inclined to "speak their mind" and express negative attributional inferences to their partner. Some support for this idea is reported by Gottman (1979), who found that spouses who were expressing negative affect nonverbally while listening to their partner were likely to express negative affect verbally in their next speaking turn. The one exception to this pattern was found for satisfied wives, who were unlikely to adopt the negative speaking role after the negative listening role. This was interpreted to suggest a "cognitive editing process" on the part of satisfied wives that serves to break cycles of negative affect. Thus, as listeners wives may have been considering unfavorable explanations for their partner's behavior, yet as the transition was made to the speaking role explanations were perhaps avoided or were articulated in a neutral tone. Rather than infer cognitive editing on the basis of overt behavioral coding, future research might be designed to study this process directly.

Second, unlike private attributions, a spouse's public attributions are accessible to the partner and may therefore serve as stimuli for the partner's behavior. Attributions typically have not been studied as interpersonal behaviors, yet examination of the dynamics that underlie public attributions may yield information concerning how spouses negotiate an understanding of the events that occur in their marriage. For example, we maintain from Figure 1 that the wife will engage in primary processing following the husband's behavior (e.g., his failure to call to say he would be late for dinner) and that a private attribution will result if the behavior is viewed as negative, unexpected, and self-relevant. In marriage, behaviors high on these dimensions are often those that fail to meet obligations or standards (e.g., "It is assumed that we will be considerate of one another"). Assuming that the husband is viewed as being the cause of his behavior and having violated the norms for expected behavior in the marriage, it is likely that he will be held responsible or accountable by the wife for his actions.

Three alternatives arise regarding how the wife might make public a private attribution when she next interacts with her husband:

1. Thinking that he failed to call because of increased pressures at work, she may provide an attribution for him ("Another hard day at work?"), and his apology ("Yeah, sorry I didn't call') might end the exchange.

2. Not knowing why the husband failed to call, but suspecting it was because he got caught up playing games on his new computer at work, she may suspend judgment yet make it evident that he has violated an expectation and request an explanation for his having done so ("You're late and you didn't callwhere have you been?") He may offer either an excuse or a justification that would mitigate his responsibility ("I'm late because they closed off one lane of traffic on the highway"), which she might challenge or seek to clarify ("Are you sure it wasn't because you were playing with your new computer?") He could justify his position further ("No-something's wrong with it and I have to send it back") before she finally decides the extent to which he is worthy of blame.

3. Believing that her husband failed to call because he is inconsiderate, she may not wait for an explanation and may im- mediately assign blame and, because she has been wronged, she will feel justified in expressing her anger ("Late again! Don't you ever worry about anyone but yourself?") The husband may try to explain ("Sorry-I had to take care of a few things at work"), respond with a counteraccusation ("I worry about myself because you are always attacking me"), or point to instances when she has violated the same expectation ("Sure, and who were you worrying about when you had the TV on until 1:00 this morning?")

Support for this analysis comes from the findings that many public attributions are devoted to self-justification (Holtzworth-Munroe \& Jacobson, 1988b) and that the interactions of distressed spouses are characterized by reciprocation of negative affect and, more specifically, by alternating accusations of blame (Gottman, 1979). In addition to corroborating existing research, consideration of public attributions is important because it underscores the distinctions drawn earlier among attributions of cause, responsibility, and blame. These judgments may not only differ in the manner specified by the presupposition model that we outlined earlier (i.e., blame presupposes responsibility, which presupposes cause), but the relations among the judgments may also differ as a function of marital satisfaction. In the earlier example, a pivotal point involved the wife's propensity, having already made attributions of cause and responsibility, to suspend judgment of blameworthiness pending evaluation of the husband's account for his behavior. It is reasonable to hypothesize that nondistressed spouses are more likely to suspend judgments of blame following a violation of behavioral standards by the partner, whereas distressed spouses may proceed immediately from judgments of responsibility to blame with little consideration of the account given by the partner for his or her actions.

This hypothesis implies that public attributions of responsibility and blame are more salient in interaction than public causal attributions, an argument that may explain HoltzworthMunroe and Jacobson's (1988b) failure to find causal attribution differences between distressed and nondistressed marriages. In addition to focusing on public attributions of responsibility or blame, greater attention might be devoted in future research to the process by which spouses seek and exchange corrective feedback for their attributions and to the strategies that spouses use to confirm and disconfirm their attributional inferences.

A third consequence of studying attributions as public events is that the methods used to examine them differ from the methods used to study private attributions. Thus, comparison of studies addressing private and public attributions is complicated not only because different phenomena are being examined, but also because the phenomena lend themselves to different assessment procedures. The most prominent methodological difference in this regard is that data on private attributions are typically provided by the subject, whereas data on public attributions (and on private attributions coded from openended material; see Camper et al., 1988; Fletcher et al., 1987; Griffin \& Foster, 1986; Holtzworth-Munroe \& Jacobson, 1985; Orvis, Kelley, \& Butler, 1976) are provided by a trained coder, who must decide whether the spouse's responses are attributions and, if so, assign them to a coding category. A limitation of the latter method is the questionable assumption that the coder can identify validly and interpret correctly the meaning 
of the spouse's attributions (Ronis, Hansen, \& O'Leary, 1983). This problem, which Russell (1982, p. 1137) labeled the "fundamental attribution researcher error," suggests the need for caution in comparing data collected from spouses' and coders' perspectives (D. H. Olson, 1977).

\section{Attributions and Primary Processing}

A processing stage is specified between partner behavior and private attribution in Figure 1 because private attributions do not follow invariably from partner behavior. Rather, the occurrence of private attributions is expected to be conditional on the outcome of primary processing. Inclusion of this stage in the framework highlights the possibility that differences in primary processing between distressed and nondistressed spouses (path f) may be responsible in part for the differences in private attributions that arise between these groups (path e). More specifcally, any relation between marital satisfaction and the occurrence of private attributions may not be due entirely to variability in attribution processes, but may instead result from a tendency on the part of distressed spouses to view partner behavior as negative, unexpected, or self-relevant. Although there is some evidence that distressed spouses view partner behaviors as more negative than the partner intended them to be (e.g., Gottman et al., 1976), there is an obvious need for research on how spouses impart meaning to partner behavior in primary processing (via path $b$ ). In the absence of such research, clinical interventions designed to change spouses' attributions (and thus change marital satisfaction, via path e) may be misguided because dysfunctional primary processing may be perpetuating marital distress (path $\mathrm{f}$ ).

One feature of primary processing that may render it dysfunctional is the degree to which a spouse attends selectively to negative partner behaviors (via path $b$ ). This may lead to a greater likelihood of private attributions (path d), which could influence subsequent behaviors (path $\mathrm{g}$ ) and marital satisfaction (directly via path e or indirectly via paths $g, a, b$, and $f$ ). Despite some research showing that distressed spouses "track" negative rather than positive partner behavior (e.g., Wills, Weiss, \& Patterson, 1974), attribution researchers have to a large degree treated spouses as passive recipients of stimuli, thus neglecting spouses' tendencies to attend selectively and actively to events in their environment. Because this approach is likely to yield an incomplete portrayal of how attributions operate in marriage, a more appropriate strategy may be one in which attributions are viewed as "components of a continuing interaction between actor and environment" (Kelley \& Michela, 1980, p. 491).

A further consequence of postulating a primary processing stage is that it makes apparent the distinction between the likelihood of a private attribution's occurring and the nature of a private attribution that has occurred. Although the nature of attributions has received far more attention (see Table 1), consideration of the likelihood of attributions raises important issues about the conditions under which attributions are likely to occur. Thus, whereas the nature of a private attribution is expected to be related to marital satisfaction (path e; see Table 3 for evidence of this relation), the likelihood of an attribution's occurring is thought to be a function of marital satisfaction (path f) and of the extent to which partner behavior is appraised (via path b) as negative, unexpected, and self-relevant.
In support of these propositions, Holtzworth-Munroe and Jacobson (1985) reported that distressed husbands were more likely than nondistressed husbands to make attributions when asked to list their thoughts and feelings in response to partner behaviors, and that across all spouses attributions were more likely for negative than for positive partner behaviors. Camper et al. (1988) replicated the latter effect, and, in a similar vein, Holtzworth-Munroe and Jacobson (1988b) found that attributions coded from marital interaction were more likely to arise when the event being explained had a negative impact on the attributor. Although subject to rival hypotheses (e.g., in Camper et al., 1988, and Holtzworth-Munroe \& Jacobson, 1985, more attributions may have occurred for negative behaviors simply because spouses listed more thoughts in response to them), the data from these studies are consistent with the idea that engaging in attributional activity allows individuals to predict and control events that might otherwise challenge their adaptation to the environment (Heider, 1958; Jones \& Davis, 1965). In addition, these studies emphasize the fact that attributions can be quantified in terms of both their number or rate and their nature. Because they may provide different information, it is important to investigate both dependent measures in future research.

\section{Attributions for Self and Partner}

In addition to examining different classes of dependent measures in future research, there is a need to expand the stimuli or independent variables that are studied. The framework outlined in Figure I shows that spouses appraise and make attributions not only for partner behavior (paths $b$ and d), but also for their own behavior (paths $\mathrm{c}$ and $\mathrm{d}$ ). Allowing for this possibility is important because the attributions that spouses make for their own behavior may serve as a standard against which partner behaviors are judged and interpreted. This process of comparison may then influence satisfaction (path e) and behavior (path g). For example, a more favorable attribution for partner behavior than for one's own behavior (e.g., "He complimented me because he really cares about how I feel; I complimented him because I wanted him to do me a favor") could lead to increased short-term satisfaction and demonstrations of affection. In contrast, a less favorable attribution for partner behavior than for one's own behavior (e.g., "He criticized me because he is immature and can never see my point of view; I criticized him because the kids were getting on my nerves") could lead to decreased short-term satisfaction and displays of anger. We can hypothesize further that the former pattern is more common among happily married spouses, whereas the latter pattern is more common among distressed spouses.

Results from a series of studies lend some support to this hypothesis. Earlier studies, which limited attribution ratings to the dimension of causal locus, reported that nondistressed spouses tended to make similar attributions for self and partner behaviors, whereas distressed spouses tended to make attributions that cast their own behavior in a positive light (Fichten, 1984; Kyle \& Falbo, 1985; see also Fincham, 1985a; Orvis et al., 1976). A subsequent study by Lavin (1987) examined a larger number of attribution dimensions and found that nondistressed spouses made similar attributions for self and partner behaviors, whereas distressed husbands tended to attribute their 
own positive behaviors to more stable, internal factors than they did for the positive behaviors of their wives. Fincham, Beach, and Baucom (1987, Studies 1 and 2) reported a similar selfpartner discrepancy in attributions of locus and globality for distressed spouses, and the effect has been extended to dimensions of responsibility attribution (Fincham \& Beach, 1988; Fincham, Beach, \& Baucom, 1987, Study 2). In addition, some evidence has been found for the complementary effect, whereby happily married spouses make more favorable attributions for their partner's behavior than they do for their own behavior (Fincham, Beach, \& Baucom, 1987, Studies 1 and 2).

Taken as a whole, these studies point to the conclusion that marital satisfaction moderates the relation between the private attributions made for one's own behavior and those made for the partner's behavior: Satisfied spouses make similar attributions for self and partner behavior, or they may exhibit a tendency toward partner-enhancing or self-effacing attributions; dissatisfied spouses exhibit a tendency toward partner-effacing or self-enhancing attributions. This phenomenon is important because it qualifies our understanding of the many studies that have examined attributions only for partner behavior, insofar as the impact of such an attribution (e.g., "He doesn't do his chores because he is lazy") may be a function of the attribution one makes for one's own behavior. Thus, a similar attribution for one's own behavior may minimize the impact of the partner's behavior ("I tend to be lazy too"), whereas a self-enhancing attribution may maximize the impact of the partner's behavior ("When I don't do my chores it's because I am too busy with work"). In short, consideration of attributions for partner behavior in relation to those made for one's own behavior appears essential to a comprehensive understanding of attributions in marriage.

Discrepancies in self-partner attributions have been studied only in relation to marital satisfaction (path e), yet it also seems likely that such discrepancies would have an impact on behavior (path g) and particularly on the affective tone of behavior. Spouses may feel justified in expressing anger as a consequence of their self-enhancing attributions ("Why don't you ever do your share of the work around here?!") and, with both spouses making such attributions, escalation of negative affect is likely to ensue. Recognition of the link between attributions and affect holds the promise of integrating the marital attribution literature with research on affect in marriage (e.g., Gottman \& Levenson, 1984) and of expanding social psychological theories of attributions and affect (e.g., Weiner, 1986) to include clinically significant, dyadic processes.

\section{Summary}

Following the rationale that theoretical clarification is a prerequisite for furthering empirical research on the role of attributions in marriage, we proposed a framework to integrate attributions, overt behavior, and marital satisfaction. Our presentation highlights the usefulness of this model (e.g., by revealing that most research investigates the direct, rather than the indirect, association between attributions and satisfaction), yet its incompleteness also must be acknowledged. Indeed, some of the variables that are emphasized may prove to be less important than others that are excluded. Independent of its validity, however, the framework is valuable because it integrates several lines of research and because it identifies numerous hypotheses for future study. Finally, the framework reveals a complexity not often evident in the marital attribution literature. Although this points to the difficulty of the task at hand, it also permits us to redefine seeming failures to replicate basic findings (e.g., Holtzworth-Munroe \& Jacobson, 1988b) as explorations of fundamentally different aspects of attribution phenomena.

\section{Summary and Discussion}

We conclude from this review that, consistent with the observations of Heider (1958), the attributions spouses make for events that occur in their marriage are related to their marital satisfaction. Compared with happily married spouses, maritally distressed spouses make causal and responsibility attributions that are likely to increase the impact of negative events and decrease the impact of positive events. Particularly strong effects were found on the causal dimension of globality, indicating that distressed spouses view the causes of negative events as globally influential in the marriage and view the causes of positive events as specific to a given incident. Research on responsibility attributions, which appear to be more salient in marriage than are causal attributions, indicates that distressed spouses tend to view their partner as selfishly motivated and behaving with negative intent. Data from experimental, clinical outcome, and longitudinal studies extend the correlational findings and suggest that attributions influence marital satisfaction rather than vice versa. Although much work remains on these and other topics, it is clear that a comprehensive understanding of marriage will be hindered to the extent that spouses' attributions are neglected.

In addition to highlighting the importance of attributions in marriage, our review indicates that the study of marital attributions has evolved through an important first stage wherein the basic association between attributions and satisfaction has been demonstrated. We have attempted to expedite the next stage of research in this domain in three ways. First, we have offered several recommendations for defining and measuring the dimensions of attributions and for distinguishing among types of attributions. Second, we have identified rival hypotheses that need to be examined in order to refine our understanding of the relation between attributions and marital satisfaction. Third, we have presented an integrative framework that, by elaborating on the association between attributions and marital satisfaction, points to several broad areas for future inquiry. Implicit in the proposal of this framework is the notion that attributions are a necessary, but by no means sufficient, component for understanding marital satisfaction. As a consequence, we made several suggestions for exploring the contribution that attributions might make to enriching the large body of research on behavior in marriage.

An underlying theme of our recommendations is that future research will be most informative to the extent that experimental operations are guided by explicit theoretical assertions. The failure to generate carefully conceived research and theory in the study of marital attributions will represent not only a disregard for the shortcomings that characterized many of the sociological investigations of marital quality, but also a foregone opportunity to understand and thereby contribute to the alleviation of marital discord. 


\section{References}

Abramson, L. Y., Seligman, M. E. P., \& Teasdale, J. (1978). Learned helplessness in humans: Critique and reformulation. Journal of $A B$ normal Psychology, 87, 49-74.

American Psychiatric Association. (1980). Diagnostic and statistical manual of mental disorders (3rd ed.). Washington, DC: American Psychiatric Association.

Antaki, C., \& Fielding, G. (1981). Research on ordinary explanations. In C. Antaki (Ed.), The psychology of ordinary explanations of social behavior (pp. 27-55). New York: Academic Press.

Arias, I., \& Beach, S. R. H. (1987). The assessment of social cognition in the context of marriage. In K. D. O'Leary (Ed.), Assessment of marital discord (pp. 109-137). Hillsdale, NJ: Erlbaum.

Arias, I., \& O'Leary, K. D. (1985). Semantic and perceptual discrepancies in discordant and nondiscordant marriages. Cognitive Therapy and Research, 9, 51-60.

Bagarozzi, D. A., \& Giddings, C. W. (1983). The role of cognitive constructs and attributional processes in family therapy. In L. R. Wolberg \& M. L. Aronson, Group and family therapy 1983 (pp. 207-219). New York: Brunner/Mazel.

Barry, W. A. (1970). Marriage research and conflict: An integrative review. Psychological Bulletin. 73, 41-54.

Baucom, D. H. (1981, November). Cognitive behavioral strategies in the treatment of marital discord. Paper presented at the meeting of the Association for Advancement of Behavior Therapy, Toronto.

Baucom, D. H. (1987). Attributions in distressed relations: How can we explain them? In S. Duck \& D. Perlman (Eds.), Intimate relationships: Development, dynamics, and deterioration (pp. 177-206). London: Sage.

Baucom, D. H., \& Adams, A. N. (1987). Assessing communication in marital interaction. In K. D. O'Leary (Ed.), Assessment of marital discord (pp. 139-181). Hillsdale, NJ: Erlbaum.

Baucom, D. H., Bell, W. G., \& Duhe, A. D. (1982, November). The measurement of couples' attributions for positive and negative dyadic interactions. Paper presented at the meeting of the Association for Advancement of Behavior Therapy, Los Angeles.

Baucom, D. H., Epstein, N., Sayers, S., \& Sher, T. G. (1989). The role of cognition in marital relationships: Definitional, methodological, and conceptual issues. Journal of Consulting and Clinical Psychology, $57,31-38$.

Baucom, D. H., \& Lester, G. W. (1986). The usefulness of cognitive restructuring as an adjunct to behavioral marital therapy. Behavior Therapy; 17, 385-403.

Baucom, D. H., Sayers, S., \& Duhe, A. (1989). Attributional style and attributional patterns among married couples. Journal of Personality and Social Psychology, 56, 596-607.

Bennun, I. (1986). Cognitive components of marital conflict. Behavioural Psychotherapy, 14, 302-309.

Berley, R. A., \& Jacobson, N. S. (1984). Causal attributions in intimate relationships: Toward a model of cognitive-behavioral marital therapy. In P. Kendall (Ed.), Advances in cognitive-behavioral research and therapy (Vol. 3, pp. 1-60). New York: Academic.

Birchler, G. R., Weiss, R. L., \& Vincent, J. P. (1975). Multimethod analysis of social reinforcement exchange between maritally distressed and nondistressed spouse and stranger dyads. Journal of Personality and Social Psychology, 31, 349-360.

Bloom, B. L., Asher, S. J., \& White, S. W. (1978). Marital disruption as a stressor: A review and analysis. Psychological Bulletin, 85, 867-894.

Bradbury, T. N., \& Fincham, F. D. (1987). Affect and cognition in close relationships: Towards an integrative model. Cognition and Emotion, 1, 59-87.

Bradbury, T. N., \& Fincham, F. D. (1988a). Assessing spontaneous attributions in marital interaction: Methodological and conceptual considerations. Journal of Social and Clinical Psychology, 7, 122130.
Bradbury, T. N., \& Fincham, F. D. (1988b). Individual difference variables in close relationships: A contextual model of marriage as an integrative framework. Journal of Personality and Social Psychology. $54,713-721$.

Bradbury, T. N., \& Fincham, F. D. (1989). Behavior and satisfaction in marriage: Prospective mediating processes. Review of Personality and Social Psychology, 10, 119-143.

Bradbury, T. N., Fincham, F. D., \& Beach, S. R. (1989). The impact of attributions in marriage: Attributions and behavior exchange in marital interaction. Unpublished manuscript.

Brewin, C., \& Antaki, C. (1987). An analysis of ordinary explanations in clinical attribution research. Journal of Social and Clinical Psychology, 5, 79-98.

Burgess, E. W., Locke, H. J., \& Thomas, M. M. (1971). The family. New York: Van Nostrand Reinhold.

Camper, P. M., Jacobson, N. S., Holtzworth-Munroe, A., \& Schmaling, K. B. (1988). Causal attributions for interactional behaviors in married couples. Cognitive Therapy and Research, 12, 195-209.

Christensen, A., Sullaway, M., \& King, C. E. (1983). Systematic error in behavioral reports of dyadic interaction: Egocentric bias and content effects. Behavioral Assessment, 5, 129-140.

Cooper, H. M. (1984). The integrative research review: A systematic approach. Beverly Hills, CA: Sage,

Critchlow, B. (1985). The blame in the bottle: Attributions about drunken behavior. Personality and Social Psychology Bulletin, 11, 258-274.

Cutrona, C. E., Russell, D., \& Jones, R. D. (1985). Cross-situational consistency in causal attributions: Does attributional style exist? Journal of Personality and Social Psychology, 47, 1043-1058.

Doherty, W. J. (1981a). Cognitive processes in intimate conflict: I. Extending attribution theory. American Journal of Family Therapy, 9 , 3-13.

Doherty, W. J. (1981b). Cognitive processes in intimate conflict: II. Efficacy and learned helplessness. American Journal of Family Therapy, 9, 35-44.

Doherty, W. J. (1982). Attribution style and negative problem solving in marriage. Family Relations, 31, 201-205.

Eidelson, R. J., \& Epstein, N. (1982). Cognition and relationship maladjustment: Development of a measure of dysfunctional relationship beliefs. Journal of Consulting and Clinical Psychology, 50, 715-720.

Eiser, J. R. (1983). From attributions to behavior. In M. Hewstone (Ed.), Attribution theory: Social and functional extensions (pp. 160-169). Oxford, England: Blackwell.

Emmelkamp, P. M. G., van Linden van den Heuvell, C., Ruphan, M., Sanderman, R., Scholing, A., \& Stroink, F. (1988). Cognitive and behavioral interventions: A comparative evaluation with clinically distressed couples. Journal of Family Psychology, 1, 365-377.

Epstein, N. (1982). Cognitive therapy with couples. The American Journal of Family Therapy, 10, 5-16.

Epstein, N., Pretzer, J. L., \& Fleming, B. (1982, November). Cognitive therapy and communication training: Comparison of effects with distressed couples. Paper presented at the meeting of the Association for Advancement of Behavior Therapy, Los Angeles.

Epstein, N., Pretzer, J. L., \& Fleming, B. (1987). The role of cognitive appraisal in self-reports of marital communication. Behavior Therapy, 18, 51-69.

Fichten, C. S. (1984). See it from my point of view: Videotape and attributions in happy and distressed couples. Journal of Social and Clinical Psychology, 2, 125-142.

Fincham, F. D. (1983). Clinical applications of attribution theory: Problems and prospects. In M. Hewstone (Ed.), Attribution theory Social and functional exiensions (pp. 187-203). Oxford, England: Blackwell.

Fincham, F. D. (1985a). Attribution processes in distressed and nondistressed couples: 2. Responsibility for marital problems. Journal of Abnormal Psychology, 94, 183-190. 
Fincham, F. D. (1985b). Attributions in close relationships. In J. H Harvey \& G. Weary (Eds.), Attribution: Basic ideas and applications (pp. 203-234). New York: Academic Press.

Fincham, F. D., \& Beach, S. R. (1988). Attribution processes in distressed and nondistressed couples: 5 . Real versus hypothetical events. Cognitive Therapy and Research, 12, 505-514.

Fincham, F. D., Beach, S. R., \& Baucom, D. H. (1987). Attribution processes in distressed and nondistressed couples: 4, Self-partner attribution differences. Journal of Personality and Social Psychology, $52,739-748$.

Fincham, F. D., Beach, S. R., \& Bradbury, T. N. (in press). Marital distress, depression, and attributions: Is the distress-attribution association a function of depression? Journal of Consulting and Clinical Psychology.

Fincham, F. D., Beach, S. R., \& Nelson, G. (1987). Attribution processes in distressed and nondistressed couples: 3. Causal and responsibility attributions for spouse behavior. Cognitive Therapy and Research, 11, 71-86.

Fincham, F. D., \& Bradbury, T. N. (1987a). The assessment of marital quality: A reevaluation. Journal of Marriage and the Family, 49, 797 809.

Fincham, F. D., \& Bradbury, T. N. (1987b). Cognitive processes and conflict in close relationships: An attribution-efficacy model. Journal of Personality and Social Psychology, 53, 1106-1118.

Fincham, F. D., \& Bradbury, T. N. (1987c). The impact of attributions in marriage: A longitudinal analysis. Journal of Personality and Social Psychology, 53, 510-517.

Fincham, F. D., \& Bradbury, T. N. (1988a). The impact of attributions in marriage: Empirical and conceptual foundations. British Journal of Clinical Psychology, 27, 77-90.

Fincham, F. D., \& Bradbury, T. N. (1988b). The impact of attributions in marriage: An experimental analysis. Journal of Social and Clinical Psychology, 7, 122-130.

Fincham, F. D., \& Bradbury, T. N. (1989a). The impact of attributions in marriage: An individual differences analysis. Journat of Social and Personal Relationships, 6, 69-85.

Fincham, F. D., \& Bradbury, T. N. (1989b). Perceived responsibility for activities in marriage: Egocentric or partner-centric bias? Journal of Marriage and the Family, 51, 27-35.

Fincham, F. D., \& Bradbury, T. N. (in press). Cognition in marriage: A program of research on attributions. In D. Perlman \& W. Jones (Eds.), Advances in personal relationships (Vol. 2). Greenwich, CT: JAI Press.

Fincham, F. D., Bradbury, T. N., \& Grych, J. H. (in press). Conflict in close relationships: The role of intrapersonal phenomena. In $\mathrm{S}$. Graham \& V. S. Folkes (Eds.), Attribution theory: Applications to achievement, mental health, and interpersonal conflict. Hillsdale, $\mathrm{NJ}$ : Erlbaum.

Fincham, F. D., \& Jaspars, J. M. (1980). Attribution of responsibility: From man the scientist to man as lawyer. In L. Berkowitz (Ed.), $A d$ vances in experimental social psychology (Vol. 13, pp. 81-138). New York: Academic Press.

Fincham, F. D., \& O'Leary, K. D. (1983). Causal inferences for spouse behavior in maritally distressed and nondistressed couples. Journal of Social and Clinical Psychology, 1, 42-57.

Fincham, F. D., \& Roberts, C. (1985). Intervening causation and the mitigation of responsibility for harm doing: II. The role of limited mental capacities. Journal of Experimental Social Psychology, 21, 178-194.

Fishman, L. T. (1986). Prisoner's wives interpretations of male criminality and subsequent arrest. Deviant Behavior, 7, 137-158.

Fletcher, G. J. O., Fincham, F. D., Cramer, L., \& Heron, N. (1987). The role of attributions in the development of dating relationships. Journal of Personality and Social Psychology, 53, 481-489.

Forsyth, D. R. (1980). The functions of attributions. Social Psychology Quarterly, 43, 184-189.
Funder, D. C. (1987). Errors and mistakes: Evaluating the accuracy of social judgments. Psychological Bulletin, 101, 75-90.

Glick, B. R., \& Gross, S. J. (1975). Marital interaction and marital conflict: A critical evaluation of current research strategies. Journal of Marriage and the Family, 37, 505-512.

Gotlib, I, H., \& Hooley, J. M. (1988). Depression and marital distress: Current status and future directions. In S. Duck (Ed.), Handbook of personal relationships: Theory, research, and interventions (pp. 543570). London: Sage.

Gottman, J. M. (1979). Marital interaction: Experimental investigations. New York: Academic Press.

Gottman, J. M, \& Levenson, R. W. (1984). Why marriages fail: Affective and physiological patterns in marital interaction. In J. C. Masters \& K. Yarkin-Levin (Eds.), Boundary areas in social and developmental psychology (pp. 67-106). New York: Academic Press.

Gottman, J. M., Markman, H., \& Notarius, C. (1977). The topology of marital conflict: A sequential analysis of verbal and nonverbal behav. ior. Journal of Marriage and the Family, 53, 461-477.

Gottman, J. M., Notarius, C., Markman, H., Banks, S., Yoppi, B., \& Rubin, M. E. (1976). Behavior exchange theory and marital decision making. Journal of Personality and Social Psychology, 34, 14-23.

Griffin, J., \& Foster, S. (1986, November). Affect and attributions in distressed and nondistressed marriages: An in-vivo comparison. $\mathrm{Pa}$ per presented at the meeting of the Association for Advancement of Behavior Therapy, Chicago.

Gurman, A. S., \& Knudson, R. M. (1978). Behavior marriage therapy: I. A psychodynamic-systems analysis and critique. Family Process, 17, 121-138.

Hamilton, V. L. (1980). Intuitive psychologist or intuitive lawyer? Alternative models of the attribution process. Journal of Personality and Social Psychology, 39, 767-772.

Hart, H. L. A. (1968). Punishment and responsibility. New York: Oxford University Press.

Harvey, J. H. (1987). Attributions in close relationships: Research and theoretical developments. Journal of Social and Clinical Psychology, $5.420-434$.

Harvey, J. H., \& Weary, G. (1984). Current issues in attribution theory and research. Annual Review of Psychology, 35, 427-459.

Harvey, J. H., Wells, G. L., \& Alvarez, M. D. (1978). Attribution in the context of conflict and separation in close relationships. In J. H. Harvey, W. J. Ickes, \& R. F. Kidd (Eds.), New directions in attribution research (Vol. 2, pp. 235-260). Hillsdale, NJ: Erlbaum.

Harvey, M. D., \& Rule, B. G. (1978). Moral evaluations and judgments of responsibility. Personality and Social Psychology Bulletin, 4, 583588.

Heider, F. (1958). The psychology of interpersonal relations. New York: Wiley.

Hicks, M. W., \& Platt, M. (1970). Marital happiness and stability: A review of research in the sixties. Journal of Marriage and the Family. $32,553-574$.

Holtzworth-Munroe, A. (1988). Causal attributions in marital violence: Theoretical and methodological issues. Clinical Psychology Review, $8,331-344$.

Holtzworth-Munroe, A., \& Jacobson, N. S. (1985). Causal attributions of married couples: When do they search for causes? What do they conclude when they do? Journal of Personality and Social Psychology $48,1398-1412$.

Holtzworth-Munroe, A., \& Jacobson, N. S. (1988a). An attributional approach to marital dysfunction and therapy. In J. E. Maddux, C. D. Stoltenberg, \& R. Rosenwein (Eds.), Social processes in clinical and counseling psychology (pp. 153-170). New York: Springer-Verlag.

Holtzworth-Munroe, A., \& Jacobson, N. S. (1988b). Toward a methodology for coding spontaneous causal attributions: Preliminary results with married couples. Journal of Social and Clinical Psychology, 7, 101-112. 
Hops, H., Wills, T. A., Patterson, G. R., \& Weiss, R. L. (1972). Marital interaction coding system. Eugene, OR: Oregon Research Institute.

Hotaling, G. T. (1980). Attribution processes in husband-wife violence. In M. A. Straus \& G. T. Hotaling (Eds.), The social causes of husbandwife violence (pp. 136-154). Minneapolis: University of Minnesota Press.

Howe, G. W. (1987). Attributions of complex cause and the perception of marital conflict. Journal of Personality and Social Psychology, 53. $1119-1128$.

Jacobson, N. S. (1984). The modification of cognitive processes in behavioral marital therapy: Integrating cognitive and behavioral intervention strategies. In K. Hahlweg \& N. S. Jacobson (Eds.), Marital interaction: Analysis and modification (pp. 285-308). New York: Guilford Press.

Jacobson, N. S., \& Margolin, G. (1979). Marital therapy: Strategies based on social learning and behavior exchange principles. New York: Brunner/Mazel.

Jacobson, N. S., McDonald, D. W., Follette, W. C., \& Berley, R. A. (1985). Attributional processes in distressed and nondistressed married couples. Cognitive Therapy and Research, 9, 35-50.

Jacobson, N. S., \& Moore, D. (1981). Spouses as observers of the events in their relationship. Journal of Consulting and Clinical Psychology, 49. 269-277.

Jacobson, N. S., Waldron, H., \& Moore, D. (1980). Toward a behavioral profile of marital distress. Joumal of Consulting and Clinical Psychology, 48, 696-703.

Jones, E. E., \& Davis, K. E. (1965). From acts to dispositions: The attribution process in person perception. In L. Berkowitz (Ed.), Advances in experimental social psychology (Vol. 2, pp. 219-266). New York: Academic.

Kelley, H. H. (1977). An application of attribution theory to research methodology for close relationships. In G. Levinger \& H. L. Raush (Eds.), Close relationships: Perspectives on the meaning of intimacy (pp. 87-113). Amherst: University of Massachusetts Press.

Kelley, H. H. (1979). Personal relationships: Their structures and processes. Hillsdale, $\mathrm{NJ}$ : Erlbaum.

Kelley, H. H., \& Michela, J. L. (1980). Attribution theory and research. Annual Review of Psychology, 31, 457-501.

Knight, J. A., \& Vallacher, R. R. (1981). Interpersonal engagement in social perception: The consequences of getting into the action. Journal of Personality and Social Psychology, 40, 990-999.

Knudson, R. M., Gurman, A. S., \& Kniskern, D. P. (1980). Behavioral marriage therapy: A treatment in transition. In C. M. Franks \& G. T. Wilson (Eds.), Annual review of behavior therapy (pp. 543-573). New York: Brunner/Mazel.

Kyle, S. O., \& Falbo, T. (1985). Relationships between marital stress and attributional preferences for own and spouse behavior. Journal of Social and Clinical Psychology, 3, 339-351.

Lavin, T. J. (1987). Divergence and convergence in the causal attributions of married couples. Journal of Marriage and the Family, 49. 7180 .

Levenson, R. W., \& Gottman, J. M. (1983). Marital interaction: Physiological linkage and affective exchange. Journal of Personality and Social Psychology, 45, 587-597.

Locke, D., \& Pennington, D. (1982). Reasons and other causes: Their role in attribution processes. Journal of Personality and Social Psychology, 42, 212-223.

Locke, H. J., \& Wallace, K. (1959). Short marital-adjustment and prediction tests: Their reliability and validity. Marriage and Family Living, 21, 251-255.

Madden, M. E., \& Janoff-Bulman, R. (1981). Blame, control, and marital satisfaction: Wives' attributions for conflict in marriage. Journal of Marriage and the Family, 43, 663-674.

Margolin, G., \& Weiss, R. L. (1978). Comparative evaluation of therapeutic components associated with behavioral marital treatments. Journal of Consulting and Clinical Psychology, 46, 1476-1486.
Metalsky, G., \& Abramson, L. Y. (1981). Attributional style: Toward a framework for conceptualization and assessment. In P. Kendall \& S. Hollon (Eds.), Assessment strategies for cognitive-behavioral inter. ventions (pp. 13-58). New York: Academic Press.

Meyer, J. P. (1980). Causal attributions for success and failure: A multivariate investigation of dimensionality, formation, and consequences. Journal of Personality and Social Psychology, 38, 704-715.

Michela, J., Peplau, L., \& Weeks, D. (1982). Perceived dimensions of attributions for loneliness. Journal of Personality and Social Psychology, 43, 929-936.

Miller, F. D., Smith, E. R., \& Uleman, J. (1981). Measurement and interpretation of situational and dispositional attributions. Journal of Experimental Social Psychology, 17, 80-95.

Miller, P. C., Lefcourt, H. M., Holmes, J. G., Ware, E. E., \& Saleh, W. E. (1986). Marital locus of control and marital problem solving. Journal of Personality and Social Psychology, 51, 161-169.

Minuchin, S. (1974). Families and family therapy. Cambridge, MA: Harvard University Press.

Munton, A. G., \& Antaki, C. (1988). Causal beliefs amongst families in therapy: Attributions at the group level. British Journal of Clinical Psychology, 27, 91-97.

Newman, H. M. (1981a). Communication within ongoing intimate relationships: An attributional perspective. Personality and Social Psychology Bulletin, 7, 59-70.

Newman, H. M. (1981b). Interpretation and explanation: Influences on communicative exchanges within intimate relationships. Communication Quarterly, 29, 123-131.

Newman, H. M., \& Langer, E. J. (1988). Investigating the development and courses of intimate relationships. In L. Y. Abramson (Ed.), Social cognition inference in clinical psychology (pp. 148-173). New York: Guilford Press.

Norton, R. (1983). Measuring marital quality: A critical look at the dependent variable. Journal of Marriage and the Family, 45, 141151.

Olson, D. H. (1977). Insiders' and outsiders' views of relationships: Research studies. In G. Levinger \& H. L. Raush (Eds.), Close relationships: Perspectives on the meaning of intimacy (pp. 115-135). Amherst: University of Massachusetts Press.

Olson, J. M., \& Ross, M. (1985). Attribution: Past, present and future. In J. H. Harvey \& G. Weary (Eds.), Attribution: Basic issues and applications (pp. 282-311). New York: Academic Press.

Orvis, B. R., Kelley, H. H., \& Butler, D. (1976). Attributional conflict in young couples. In J. H. Harvey, W. Ickes, \& R. F. Kidd (Eds.), New directions in attribution research (Vol. 1, pp. 353-386). Hillsdale, NJ: Erlbaum.

Passer, M. W., Kelley, H. H., \& Michela, J. L. (1978). Multidimensional scaling of the causes for negative interpersonal behavior. Journal of Personality and Social Psychology, 36, 951-962.

Raush, H. L., Barry, W. A., Hertel, R. K., \& Swain, M. A. (1974). Communication, confict, and marriage. San Francisco: Jossey-Bass.

Regan, D. T., \& Totten, J. (1975). Empathy and attribution: Turning observers into actors. Journal of Personality and Social Psychology. $32,850-856$.

Rempel, J. K., Holmes, J. G., \& Zanna, M. P. (1985). Trust in close relationships. Journal of Personality and Social Psychology, 49, 95112.

Revenstorf, D. (1984). The role of attribution of marital distress in therapy. In K. Hahlweg \& N. S. Jacobson (Eds.), Marital interaction: Analysis and modification (pp. 325-336). New York: Guilford Press.

Robins, C. (1988). Attributions and depression: Why is the literature so inconsistent? Journal of Personality and Social Psychology, 54, 880 889.

Ronis, D. L., Hansen, R. D., \& O'Leary, V. B. (1983). Understanding the meaning of achievement attributions: $A$ test of derived locus and stability scores. Journal of Personality and Social Psychology, 44. $702-711$. 
Ross, M., \& Sicoly, F. (1979). Egocentric biases in availability and attribution. Journal of Personality and Social Psychology, 37, 322-336.

Rubin, Z. (1973). Liking and loving. New York: Holt, Rinehart \& Winston.

Rubin, Z., Peplau, L. A., \& Hill, C. T. (1981). Loving and leaving: Sex differences in romantic attachments. Sex Roles, 7, 821-835.

Russell, D. (1982). The causal dimension scale: A measure of how individuals perceive causes. Journal of Personality and Social Psychology, 42, 1137-1145.

Russell, D., McAuley, E., \& Tarico, V. (1987). Measuring causal attributions for success and failure: A comparison of methodologies for assessing causal dimensions. Journal of Personality and Social Psychology, 52, 1248-1257.

Sagatun, I. J. (1982). Attributional effects of therapy with incestuous families. Journal of Marital and Family Therapy, 8, 99-104.

Schaap, C. (1984). A comparison of the interaction of distressed and nondistressed married couples in a laboratory situation: Literature survey, methodological issues, and an empirical investigation. In $\mathrm{K}$. Hahlweg \& N. S. Jacobson (Eds.), Marital interaction: Analysis and modification (pp. 133-158). New York: Guilford Press.

Schindler, L., \& Vollmer, M. (1984). Cognitive perspectives in behavioral marital therapy: Some proposals for bridging theory, research, and practice. In K. Hahlweg \& N. S. Jacobson (Eds.), Marital interaction: Analysis and modification (pp. 309-324). New York: Guilford Press.

Schriber, J. B., Larwood, L., \& Peterson, J. L. (1985). Bias in the attribution of marital conflict. Journal of Marriage and the Family, 47, 717-721.

Seligman, C., Fazio, R. H., \& Zanna, M. P. (1980). Effects of salience of extrinsic rewards on liking and loving. Journal of Personality and Social Psychology, 38, 453-460.

Shaver, K. G. (1981). Back to the basics: On the role of theory in the attribution of causality. In J. H. Harvey, W. Ickes, \& R. F. Kidd (Eds.), New directions in attribution research (Vol. 3, pp. 331-358). Hillsdale, NJ: Erlbaum.

Shaver, K. G. (1985). The attribution of blame: Causality, responsibility, and blameworthiness. New York: Springer-Verlag.

Shaver, K. G., \& Drown, D. (1986). On causality, responsibility, and self-blame: A theoretical note. Journal of Personality and Social Psychology, 50, 697-702.

Shultz, T. R., \& Schleifer, M. (1983). Towards a refinement of attribution concepts. In J. Jaspars, F. D. Fincham, \& M. Hewstone (Eds.), Attribution theory and research: Conceptual, developmental, and social dimensions (pp. 37-62). New York: Academic Press.

Shultz, T. R., Schleifer, M., \& Altman, I. (1981). Judgments of causation, responsibility and punishment in cases of harm-doing. Canadian Journal of Behavioral Science, 13, 238-253.

Sillars, A. L. (1985). Interpersonal perception in relationships. In W. Ickes (Ed.), Compatible and incompatible relationships (pp. 277305). New York: Springer-Verlag.

Solomon, S. (1978). Measuring dispositional and situational attributions. Personality and Social Psychology Bulletin, 4, 589-594.

Spanier, G. B. (1976). Measuring dyadic adjustment: New scales for assessing the quality of marriage and similar dyads. Journal of Marriage and the Family, 38, 15-28.

Stephen, T. (1987). Attribution and adjustment to relationship termination. Journal of Social and Personal Relationships, 4, 47-61.

Stratton, P., Heard, D., Hanks, H. G. I., Munton, A. G., Brewin, C. R., \& Davidson, C. (1986). Coding causal beliefs in natural discourse. British Journal of Social Psychology, 25, 299-313.

Sweeney, P. D., Anderson, K., \& Bailey, S. (1986). Attributional style in depression: A meta-analytic review. Journal of Personality and Social Psychology, 50, 974-991.

Taylor, S. E., \& Koivumaki, J. H. (1976). The perception of self and others: Acquaintanceship, affect, and actor-observer differences. Journal of Personality and Social Psychology, 33, 403-406.

Tharp, R. G. (1963). Psychological patterning in marriage. Psychological Bulletin, 60, 97-117.

Thompson, S. C., \& Kelley, H. H. (1981). Judgments of responsibility for activities in close relationships. Journal of Personality and Social Psychology, 41, 469-477.

Thompson, J. S., \& Snyder, D. K. (1986). Attribution theory in intimate relationships: A methodological review. The American Journal of Family Therapy, 14, 123-138.

Veroff, J., Kulka, R. A., \& Douvan, E. (1981). Mental health in America: Patterns of help-seeking from 1957-1976. New York: Basic Books.

Vincent, J. P., Weiss, R. L., \& Birchler, G. R. (1975). A behavioral analysis of problem-solving in distressed and nondistressed and stranger dyads. Behavior Therapy, 6, 475-487.

Weiner, B. (1985a). An attributional theory of achievement motivation and emotion. Psychological Review, 92, 548-573.

Weiner, B. (1985b). "Spontaneous" causal search. Psychological Bulletin, 97, 74-84.

Weiner, B. (1986), An attributional theory of motivation and emotion. New York: Springer-Verlag.

Weiss, R. L. (1980). Strategic behavioral marital therapy: Toward a model for assessment and intervention. In J. P. Vincent (Ed.), $A d$ vances in family intervention, assessment and theory (pp. 229-271). Greenwich, CT: JAI Press.

Weiss, R. L., \& Perry, B. A. (1979). Assessment and treatment of marital dysfunction. Eugene, OR: Oregon Marital Studies Program.

Wills, T. A., Weiss, R. L., \& Patterson, G. R. (1974). A behavioral analysis of the determinants of marital satisfaction. Journal of Consulting and Clinical Psychology, 42, 802-811.

Wimer, S., \& Kelley, H. H. (1982). An investigation of the dimensions of causal attribution. Joumal of Personality and Social Psychology, 43, 1142-1162.

Wright, J., \& Fichten, C. (1976). Denial of responsibility, videotape feedback and attribution theory: Relevance for behavioral marital therapy. Canadian Psychology Review, 17, 219-230.

Received September 22, 1987

Revision received December 7, 1988

Accepted December 19, 1988 